The University of Maine

DigitalCommons@UMaine

Publications

Senator George J. Mitchell Center for Sustainability

Solutions

2013

\title{
Mapping, Modeling, and the Fragmentation of Environmental Law.
}

Dave Owen

University of Maine School of Law

Follow this and additional works at: https://digitalcommons.library.umaine.edu/ mitchellcenter_pubs

Part of the Environmental Law Commons, and the Environmental Policy Commons

\section{Repository Citation}

Owen, Dave, "Mapping, Modeling, and the Fragmentation of Environmental Law." (2013). Publications. 79.

https://digitalcommons.library.umaine.edu/mitchellcenter_pubs/79

This Article is brought to you for free and open access by DigitalCommons@UMaine. It has been accepted for inclusion in Publications by an authorized administrator of DigitalCommons@UMaine. For more information, please contact um.library.technical.services@maine.edu. 


\section{University of Maine}

From the SelectedWorks of David R Owen

February 29, 2012

\section{Mapping, Modeling, and the Fragmentation of Environmental Law}

David R Owen 


\title{
MAPPIng, Modeling, AND THE Fragmentation OF ENVIRONMENTAL LAW Dave Owen*
}

\begin{abstract}
In the past forty years, environmental researchers have achieved major advances in electronic mapping and spatially explicit, computer-based simulation modeling. Those advances have turned quantitative spatial analysis - that is, quantitative analysis of data coded to specific geographic locations - into one of the primary modes of environmental research. Researchers now routinely use spatial analysis to explore environmental trends, diagnose problems, discover causal relationships, predict possible futures, and test policy options. At a more fundamental level, these technologies and an associated field of theory are transforming how researchers conceptualize environmental systems.
\end{abstract}

Advances in spatial analysis have had modest impacts upon the practice of environmental law, little impact on environmental law's structure or theory, and minimal impact on environmental law research. However, the potential legal implications of these advances are profound. By focusing on several of environmental law's traditional core debates, and by using urban development as a central example, this Article explores those implications. It shows that spatial analysis can change the problems environmental law addresses, the regulatory instruments environmental law uses, the entities law empowers to address those problems, and the methodologies of environmental law research.

\section{TABLE OF CONTENTS}

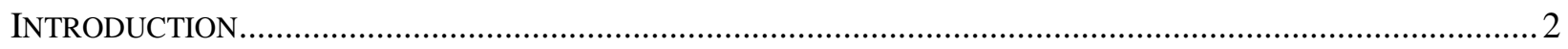

I. THE PERSISTENT FRAGMENTATION OF ENVIRONMENTAL LAW ….................................................... 8

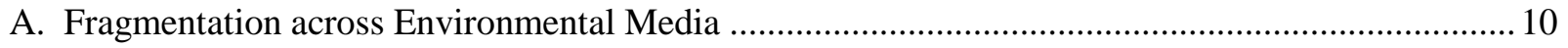

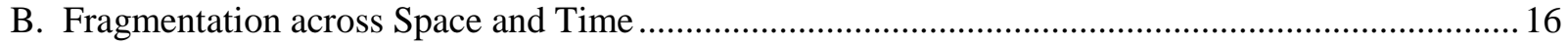

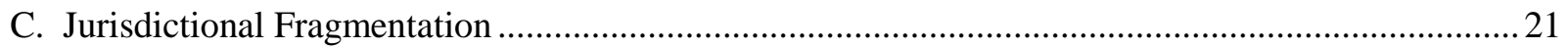

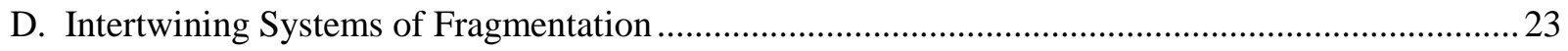

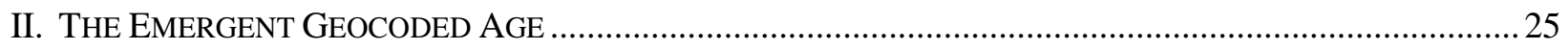

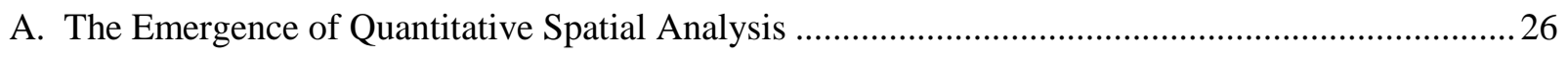

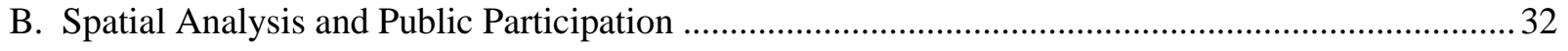

III. Spatial ANAlysis, ENVIRONMENTAL LAW, AND THE CHALLENGES OF GREENACRES .................... 37

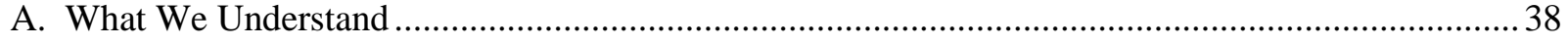

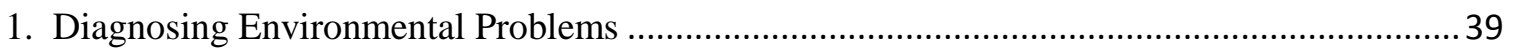

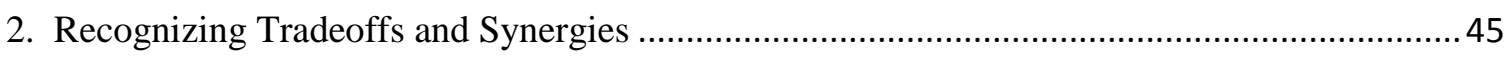

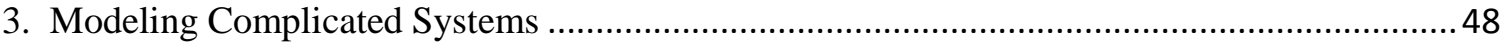

B. How We Regulate: Changing Legal Instrument Selection...........................................................52 
1. Muddling toward Synoptic Regulation

2. Making Environmental Trading Systems Work ............................................................... 55

C. Who Regulates: Toward a More Functional Federalism.............................................................61

IV. SPATIAL ANALYSIS AND ENVIRONMENTAL LAW RESEARCH METHODOLOGIES................................67

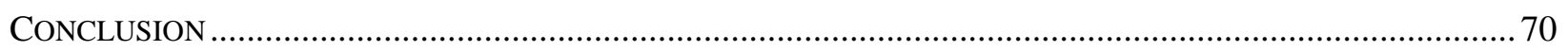

\section{INTRODUCTION}

Imagine a proposed housing development — call it "Greenacres" — at the fringe of a metropolitan area. Greenacres will contain several dozen new homes, all constructed on one- to five-acre lots. ${ }^{1}$ The developer plans to clear forests, fill wetlands, and replace undeveloped wildlife habitat with buildings, pavement, and landscaped yards. Stormwater runoff from Greenacres will pollute local streams and increase flooding risk, and the new roads, buildings, and driveways will limit groundwater recharge, reducing local water supplies even as the houses increase water demand. ${ }^{2}$ The houses also will consume energy, most likely from fossil fuels, and the residents will burn gasoline while they drive, generating conventional air pollutant and

* Associate Professor, University of Maine School of Law. Research for this article was supported by National Science Foundation award EPS-0904155 to Maine EPSCoR at the University of Maine and by the University of Maine School of Law. I think Todd Aagaard, Dmitry Bam, Eric Biber, Dan Farber, Kelley Hart, Rita Heimes, Blake Hudson, Michelle Johnson, Rebecca Purdom, Sarah Schindler, Sean Smith, Sarah Tran, Jennifer Wriggins, and participants at workshops at Vermont Law School and the University of Maine for comments on earlier drafts, and Daniel D'Alessandro, Robin Campbell, John O'Hara, and Lauren Parker for research assistance.

${ }^{1}$ This type of "exurban" development has rapidly expanded in recent decades. See Andrew J. Hansen et al., Effects of Exurban Development on Biodiversity: Patterns, Mechanisms, and Research Needs, 15 ECOLOGICAL APPLICATIONS 1893, 1893-94 (2005).

${ }^{2}$ See Dave Owen, Urbanization, Water Quality, and the Regulated Landscape, 82 U. Colo. L. ReV. 431, 439-45 (2011); see, e.g., ROBERT GLENNON, WATER FOLLIES: GROUNDWATER PUMPING AND THE FATE OF AMERICA's FRESH WATERS 99-111 (2002). 
greenhouse gas emissions. ${ }^{3}$ Greenacres also will bring benefits: profits for the current landowner and the developer; construction jobs; new housing options; an increased tax base; and potential customers and employees for area businesses. But those benefits come with a price.

If viewed in isolation, each of these impacts might seem like a drop in a bucket, not at all worthy of regulatory oversight or response. ${ }^{4}$ When viewed in combination, however, and when combined with the impacts of other similar developments, Greenacres' consequences might seem problematic. A regulator taking that holistic view might conclude that development should occur elsewhere, or that it need not occur at all. ${ }^{5}$ More plausibly, the regulator might negotiate changes that reduce or compensate for some of Greenacres' impacts. ${ }^{6}$ That broader perspective might also spur the adoption of legal measures to address the larger environmental impacts to which Greenacres is contributing. ${ }^{7}$ Not surprisingly, environmental commentators have spent decades arguing for such holistic review. ${ }^{8}$ Calls are legion for policymakers to consider their decisions'

\footnotetext{
${ }^{3}$ See generally COMMITTEE FOR THE STUdy On THE RELATIONSHIPS AMONG DEVElopMENT PATTERnS, Vehicle Miles TRAVELED, AND ENERGy CONSUMPTION ET AL, DRIVING AND THE BUILT ENVIRONMENT: THE EFFECTS OF COMPACT DEVELOPMENT ON MOTORIZED TRAVEL, ENERGY USE, AND CO2 EMISSIONS (2009) (hereinafter DRIVING AND THE BUILT ENVIRONMENT); TRANSP. AIR QUALITY CTR., U.S. EPA, EPA GUIDANCE: IMPROVING AIR QUALITY THROUGH LAND USE ACTIVITIES (2001).

${ }^{4}$ See Kevin M. Stack \& Michael P. Vandenbergh, The One Percent Problem, 111 CoLUM. L. REV. 1385, 1398-1402 (2011); David M. Theobald et al., Ecological Support for Rural Land-Use Planning, 15 ECOLOGICAL APPLICATIONS 1906, 1908 ("The aggregate effect of land-use change is the result of many, relatively small individual decisions that are diffuse in space and time, made by a diverse array of planners and policymakers."); William E. Odum, Environmental Degradation and the Tyranny of Small Decisions, 32 BIOSCIENCE 728, 728 (1982).

${ }^{5}$ For discussion of the non-environmental costs of development, see ALAN MALLACH, BRINGING BuILdings BACK: From ABANDONED PROPERTIES TO COMMUNITY AsseTs 3-7 (2006); David Streitfield, In the Central Valley, the Ruins of the Housing Bust, N.Y. TIMES, August 23, 2008, at BU1.

${ }^{6}$ This sort of negotiation is more common than flat prohibitions. See, e.g., Dave Owen, Critical Habitat and the Challenge of Regulating Small Harms, 64 FLA. L. REV. 141, 183-84 (2012) (documenting the prevalence of negotiated outcomes in Endangered Species Act consultations); Daniel A. Farber, Taking Slippage Seriously: NonCompliance and Creative Compliance in Environmental Law, 23 HARV. ENVTL. L. REV. 297, 298-99 (1999).

${ }^{7}$ For discussion of the ways that "[c]hanging [c]onceptions of [t]ime and [s]pace" influenced environmental law's formation, see RICHARD LAZARUS, THE MAKING OF ENVIRONMENTAL LAW 54-66 (2004).

${ }^{8}$ See infra Part I; see, e.g., Cass R. Sunstein, Beyond the Precautionary Principle, 151 U. PA. L. REV. 1003, 1011 (2003) ("regulators should use a wide rather than narrow viewscreen"); Craig Anthony (Tony) Arnold, Fourth Generation Environmental Law: Integrationist and Multimodal, 35 WM. \& MARY ENVTL. L.J. 771, 776 (critiquing "[u]nimodal and fragmented responses to complex and multidimensional environmental problems").
} 
impacts upon a wider variety of environmental, social, and economic outcomes $;^{9}$ to consider broader spatial and temporal trends when making those decisions $;^{10}$ and to involve more entities, both public and private, in decision-making processes. ${ }^{11}$

Unfortunately, those aspirations have been difficult to fulfill. Environmental problems are notoriously complex, ${ }^{12}$ and considering the impacts of a range of activities, all dispersed across space and time, upon a variety of environmental media can be exceedingly challenging. ${ }^{13}$ The challenges become even greater when, as is often the case, knowledge of an activity's environmental impacts, opinions about the importance of those impacts, and the capacity to respond all are dispersed among many entities, both within and outside government. ${ }^{14}$ A central conflict of environmental law therefore has pitted the desire for holistic decision-making against the obvious need to keep decision-makers' tasks manageably discrete. ${ }^{15}$ For decades, legal commentators have been debating how this tension should be resolved. ${ }^{16}$

${ }^{9}$ See, e.g., Richard B. Stewart, A New Generation of Environmental Regulation?, 29 CAP. U. L. REV. 21, 21 (2001) (summarizing these critiques); see infra Part I.

${ }^{10}$ See, e.g., Grand Canyon Trust v. Fed. Aviation Admin., 290 F.3d 339, 346 (D.C. Cir. 2002) (setting aside an environmental analysis because it "treat(ed) the identified environmental concern in a vacuum, as an incremental approach attempts").

${ }^{11}$ See, e.g., Jody Freeman \& Daniel A. Farber, Modular Environmental Regulation, 54 DUKE L.J. 795, 79798 (2005) ("There is rarely a single tool, or a lone agency at either the federal or state level, that is capable of producing the desired environmental benefit by itself."); Jody Freeman, Collaborative Governance in the Administrative State, 45 UCLA L. REV. 1, 28-29, 31-33 (1997).

${ }^{12}$ See generally LAZARUS, supra note 7, at 6-19.

${ }^{13}$ See, e.g., William W. Buzbee, Urban Sprawl, Federalism, and the Problem of Institutional Complexity, 68 Fordham L. ReV. 57, 57 (1999); Joseph L. SAX, DEFENDING THE ENVIRONMENT: A STRATEGY FOR CITIZEN ACTION 56 (1970) ("The greatest problems are often the outcome of the smallest-scale decisions because the ultimate, aggregate impacts of those decisions are so difficult to see and the pressures so difficult to cope with....").

${ }^{14}$ See Freeman \& Farber, supra note 11, at 797-98.

${ }^{15}$ For exploration of this debate, see James E. Krier \& Mark Brownstein, On Integrated Pollution Control, 22 ENVTL. L. 119 (1992).

${ }^{16}$ See, e.g., Wendy E. Wagner, Commons Ignorance: The Failure of Environmental Law to Produce Needed Information on Health and the Environment, 53 DUKE L.J. 1619, 1623-24, 1720-26 (2004) (arguing that "idyllic assumptions" about information availability distort debates about environmental law); Bruce A. Ackerman \& Richard B. Stewart, Reforming Environmental Law, 37 STAN. L. REV. 1333, 1336-37 (1985) (arguing that incentive-based regulation ameliorates informational challenges created by alternative regulatory approaches). 
Meanwhile, other environmental disciplines have been evolving, and that evolution has significant but largely unappreciated implications for these debates. Over the past four decades, a series of technological advances has transformed environmental planning and research. ${ }^{17}$ Increased data availability, new software systems, and increased computing power have combined to turn spatial analysis - that is, quantitative analysis of data coded to specific geographic coordinates - into the coin of the environmental realm. ${ }^{18}$ At federal, state, and local government offices, in the private sector, and throughout non-legal academia, thousands of analysts in dozens of fields now spend their days gathering and crunching spatial data. ${ }^{19}$ Their efforts serve a variety of purposes,${ }^{20}$ and, more fundamentally, are leading to new ways of conceptualizing ecological systems and environmental change. ${ }^{21}$

\footnotetext{
${ }^{17}$ See infra Part II. The transformation extends well beyond environmental management and research. See, e.g., National Geospatial-Intelligence Agency, Who We Are, https://www1.nga.mil/About/WhoWeAre/Pages/default.aspx (last visited September 12, 2011) (describing activities of an agency that uses spatial data and analysis to promote national security); See LAXMI RAMASUBRAMANIAN, GEOGRAPHIC INFORMATION SCIENCE AND PUBLIC PARTICIPATION 16 (2010) (describing the use of geographic data to prove racial redlining in insurance policy sales); KeITH HARRIES, MAPPING CRIME: PRINCIPLE AND PRACTICE (1999).

${ }^{18}$ See id.; Jacek Malczewski, GIS-based land-use suitability analysis: a critical overview, 62 PROGRESS IN PLANNING 3, 5 (2004) ("GIS-based land-use suitability techniques have increasingly become integral components of urban, regional and environmental planning activities."). One author defines "spatial analysis" as representing "a collection of techniques and models that explicitly use the spatial referencing associated with each data value or object that is specified within the system under study." ROBERT P. HAINING, SPATIAL DATA ANALYSis: THEORY AND PRACTICE 4 (2003).

${ }^{19}$ See Michael Keating, GIS/geospatial sales projected to grow 8.3 percent in 2011, GovPRO (January 27, 2011, at 3:15 PM), http://govpro.com/technology/gis_gps/gis-geospatial-growth-20110127/ (describing multi-billion dollar sales and steady growth).

${ }^{20}$ See, e.g., Greenprinting, THE TRUST FOR PUBLIC LAND, http://www.tpl.org/what-wedo/services/conservation-vision/greenprinting.html (last visited August 24, 2011) (creating maps to guide land conservation); Alex Kuffner, R.I. 's offshore-wind mapping is held up as model, PROVIDENCE JOURNAL, May 29, 2011; Gerard Hoek et al., A review of land-regression models to assess spatial variation of outdoor air pollution, 42 ATMOSPHERIC ENV'T 7561 (2008); Tenley M. Conway \& Richard G. Lathrop, Alternative land use regulations and environmental impacts: assessing future land use in an urbanizing watershed, 71 LANDSCAPE AND URBAN PLANNING 1 (2005).

${ }^{21}$ See, e.g., MARINA ALBERTI, AdVANCES IN URBAN ECOLOGY: INTEGRATING HUMANS AND ECOLOGICAL PROCESSES IN URBAN ECOSYSTEMS (2008); see also NATIONAL RESEARCH COUNCIL, GRAND CHALlENGES IN ENVIRONMENTAL SCIENCES 4 (2001) (identifying spatial modeling of land use change as one of the greatest future challenges for environmental science).
} 
The emergence of spatial analysis merits revisiting environmental law's traditional debates about integrative, holistic decision-making. Spatial analysis can facilitate better assessments of the cumulative consequences of multiple environmental decisions dispersed across space and time. By enabling analysts to address a variety of impacts, spatial tools and models can allow simultaneous pursuit of multiple environmental goals. ${ }^{22}$ And by producing maps, which are a compelling and accessible means of conveying information, spatial analysis can improve communication among the many entities involved in environmental policymaking. ${ }^{23}$ In short, spatial analysis can facilitate more integrative approaches to environmental law. Spatial analysis technologies are by no means perfect tools, and they cannot turn environmental regulators into omniscient seers. ${ }^{24}$ But they still can change our understanding of and approaches to environmental protection.

Despite that potential, legal thinkers have devoted little attention to spatial analysis. Legal-academic literature does contain abundant references to geographic information systems (GIS), and most practicing environmental lawyers are at least vaguely aware of the increasing pervasiveness of spatial analysis tools. ${ }^{25}$ Environmental law researchers also increasingly draw on non-legal literature, and many of the scientific and economic articles they cite draw on spatial analysis. But very few legal authors have considered whether emerging spatial analysis techniques hold transformative potential for either the practice or theory of environmental law,

\footnotetext{
${ }^{22}$ See, e.g., Theodore C. Weber \& William L. Allen, Beyond on-site mitigation: An integrated, multi-scale approach to environmental mitigation and stewardship for transportation projects, 96 LANDSCAPE AND URBAN PlanNing 240 (2010). For more discussion, see infra Part III.

${ }^{23}$ See infra Part III.

${ }^{24}$ See infra notes $165-170$ and accompanying text.

${ }^{25}$ As of October 3, 2011, a search of Westlaw's journals and law reviews database for the phrase "geographic information system" produced 658 hits. Most of these articles contained passing references to GIS systems, and the articles that discuss GIS in more depth generally focus on evidentiary issues and privacy questions. 
let alone put those techniques to use. ${ }^{26}$ Even as other research fields move toward quantitative analysis based on spatial data, environmental law research remains largely the domain of qualitative argument, often grounded in intuition and anecdote and delivered exclusively in prose. $^{27}$

This Article argues for bridging the divide between spatial analysis and environmental law. Part I summarizes some of the classic fragmentation challenges of environmental law, and thus maps problems that spatial analysis might help law address. It first discusses fragmentation of different environmental regulatory programs, then fragmentation across space and time, and then federalism-based debates about decision-making authority. Part II turns from traditional legal debates to the technological and theoretical evolution of spatial analysis. Part III explores some of spatial analysis's implications for environmental law. Using land use change as a central example, it explains how spatial analysis can change which environmental problems we find cognitively tractable, what tools we use to address those problems, and to whom we allocate authority to respond. Finally, Part IV turns from legal implementation to legal research, and explains how spatial analysis could advance academic inquiries about environmental law.

\footnotetext{
${ }^{26}$ For rare exceptions to this generalization, see Patricia E. Salkin, GIS for the Practicing Attorney, SL005 ALI-ABA 951 (2005); Patricia E. Salkin \& John R. Nolon, Practically Grounded: Convergence of Land Use Law Pedagogy and Best Practices, 60 J. LegAL EduC. 519, 532 (2011); William Boyd, Ways of Seeing in Environmental Law: How Deforestation Became an Object of Climate Governance, 37 ECOLOGY L.Q. 843 (2010) (arguing that spatial imaging and analysis led policymakers to a new understanding of deforestation problems); Nicklas A. Akers, New Tools for Environmental Justice: Articulating A Net Health Effects Challenge to Emissions Trading Markets, 7 Hastings W.-N.W. J. ENVTL. L. \& PoL'Y 203, 219-21 (2001); Vicki Been \& Francis Gupta, Coming to the Nuisance or Going to the Barrios? A Longitudinal Analysis of Environmental Justice Claims, 24 ECOLOGY L.Q. 1, 10-19 (1997) (using spatially coded data to investigate environmental injustice claims). See also Daniel C. Esty, Environmental Protection in the Information Age, 79 N.Y.U. L. REV. 115 (2004) (considering the environmental law implications of a range of information technologies). Economists also sometimes use spatial data to investigate how regulated entities respond to legal incentives. See, e.g., Dean Lueck \& Jeffrey A. Michael, Preemptive Habitat Destruction Under the Endangered Species Act, 46 J.L. \& ECON. 27 (2003) (analyzing landowner responses to section 9 of the ESA); Elena G. Irwin et al., Modeling and Managing Urban Growth at the Rural-Urban Fringe: A Parcel-Level Model of Residential Land Use Change, 32 AGRIC. \& RESOURCE ECON. REV. 83 (2003) (evaluating the effects of various land use controls).

${ }^{27}$ With the emergence of empirical legal studies, the primacy of qualitative argument is fading. But empirical legal scholars generally have not used the kinds of geographically coded databases described in this Article.
} 
Throughout, the Article also discusses limitations of spatial analysis, which can suffer from the opacity, manipulability, and false certainty that plague any complex and quantitative mode of analysis. ${ }^{28}$ It does not claim that spatial analysis will readily or easily solve environmental law's challenges, and in some circumstances spatial analysis tools will be too reductionist or too cumbersome to improve environmental regulation or research. Nor do I argue that better information will always lead to better decisions. As the politics of climate change have thoroughly demonstrated, such an expectation is unduly optimistic. ${ }^{29}$ But despite these limitations, the emergence of spatial analysis is an important, and potentially quite positive, development for environmental law.

\section{The Persistent Fragmentation OF EnVironmental LAW}

The years 2008 and 2009 brought the Atlanta metropolitan region too much sun, too little rain, and a big legal scare. For decades, the metropolitan area had grown rapidly, piling one Greenacres-style development upon another and becoming a poster child for suburban sprawl. ${ }^{30}$ Greater Atlanta's growth led to massive increases in water use, and when drought struck, the Atlanta region was stretching the limits of its water supply. ${ }^{31}$ Then the United States Court of Appeals for the D.C. Circuit and a federal district court held that greater Atlanta was using water

${ }^{28}$ See generally Wendy Wagner et al., Misunderstanding Models in Environmental and Public Health Regulation, 18 N.Y.U. ENVTL. L. J. 293 (2010); Kenneth A. Bamberger, Technologies of Compliance: Risk and Regulation in a Digital Age, 88 TEX. L REV. 669, 675-76 (2010) (describing the role of automated risk modeling software in the 2008 financial collapse); James D. Fine \& Dave Owen, Technocracy and Democracy: Conflicts Between Models and Participation in Environmental Law and Planning, 56 HASTINGS L.J. 901 (2005).

${ }^{29}$ See generally Irene Lorenzoni \& Mike Hulme, Believing is seeing: laypeople's views of future socioeconomic and climate change in England and Italy, 18 PUB. UNDERSTANDING SCI. 383, 393-94 (2009) (finding that prior beliefs influence people's willingness to accept new information).

${ }^{30}$ See The Sprawl Index: Atlanta, GA, SMART GrowTH AMERICA, http://www.smartgrowthamerica.org/sprawlindex/factsheet_atlanta.html (last visited October 31, 2011).

${ }^{31}$ See Benjamin L. Snowden, Bargaining in the Shadow of Uncertainty: Understanding the Failure of the ACF and ACT Compacts, 13 N.Y.U. ENVTL. L.J. 134, 139 (2005) (describing Atlanta's water supply strains). 
to which it had no legal entitlement, raising the specter of legal limits atop the natural drought. ${ }^{32}$

Atlanta, it seemed, had grown far beyond its hydrologic means.

The drought has since ended, and an Eleventh Circuit decision provided a respite, at least, from the apparent water supply disaster. ${ }^{33}$ But water conflict continues, and many other growth problems persist. ${ }^{34}$ Atlanta has not attained federal air quality standards, and its non-attainment status is partly caused by a sprawling, automobile-dependent pattern of growth. ${ }^{35}$ At the region's urban fringe, development has clashed with the protective mandates of the Endangered Species Act (ESA). ${ }^{36}$ Other social and environmental problems associated with sprawl-traffic congestion, for example, and isolation of people (particularly the socially and economically disadvantaged) from workplaces, services, and each other-continue to plague the region. ${ }^{37}$ While Atlanta may present an extreme case, it is not unique. Similar tensions between development and environmental quality recur across much of the country. ${ }^{38}$

These tensions did not arise in a legal void. Many growth areas boomed after the early 1970s, when a series of federal and state statutes created legal standards that environmental

\footnotetext{
${ }^{32}$ Se. Fed. Power Customers, Inc. v. Geren, 514 F.3d 1316 (D.C. Cir. 2008); In re Tri-State Water Rights Litig., 639 F.Supp.2d 1308 (M.D. Fla. 2009), rev'd, 644 F.3d 1160 (11th Cir. 2011).

${ }^{33}$ See In re MDL-1824 Tri-State Water Rights Litig., 644 F.3d 1160, 1166 (11th Cir. 2011) (holding that the Army Corps of Engineers did have authority to deliver water to Atlanta).

${ }^{34}$ See Carole Rutland, No way to run a river, COLUMBUS LEDGER-ENQUIRER, Nov. 27, 2011 ("The case now lingers as Alabama and Florida think about their next move.").

${ }^{35}$ See Larry Hartstein, Atlanta's Air Quality: Better, But Still Bad, THE AtLanta Journal-Constitution, April 29, 2010; Michael Lewyn, How City Hall Causes Sprawl: A Case Study, 30 EcOLOGY L.Q. 189, $191-92$ (2003) (reviewing LARRY KeAting, ATlanta: RACE, Class, AND URBAN EXPANSION (2001)).

${ }^{36}$ See Seth J. Wenger et al., Runoff Limits: An Ecologically-Based Stormwater Management Program, 9 STORMWATER 1 (2008) (describing impacts on protected aquatic species in the Etowah watershed).

${ }^{37}$ See Robert D. Bullard et al., The Costs and Consequences of Suburban Sprawl: The Case of Metro Atlanta, 17 GA. ST. U. L. REV. 935 (2001).

${ }^{38}$ See, e.g, Lincoln Davies, Just a Big, 'Hot Fuss'? Assessing the Value of Connecting Suburban Sprawl, Land Use, and Water Rights Through Assured Supply Laws, 34 ECOLOGY L.Q. 1217, 1219-25 (2007) (discussing tensions between growth and waters supplies); Ben Giles, Chesapeake Bay cleanup could cost Prince George's $\$ 800$ million, WASHINGTON EXAMINER, Nov. 27, 2011 (describing the costs of water pollution, partly derived from urbanization, in Chesapeake Bay).
} 
conditions in these areas now fail to attain. ${ }^{39}$ Nor did these problems emerge because growing populations inevitably mean environmental degradation. By regulating the configuration, layout, and landscaping of developments, communities can minimize or mitigate many environmental impacts, sometimes while imposing relatively small costs on developers and creating more livable communities. ${ }^{40}$ Instead, one important reason why greater Atlanta and its sprawling brethren have grown problematically is that it is exceedingly difficult for any single entity to grasp, let alone address, the full range of impacts of sprawl. ${ }^{41}$

That challenge exemplifies an often-criticized feature of the United States'system of environmental law. Too often, critics argue, environmental law depends upon regulatory agencies addressing one environmental goal and one project at a time, and doing so with insufficient involvement from other agencies, levels of government, affected firms, or members of the public. ${ }^{42}$ While alternative approaches exist, their informational demands can strain the cognitive capacities of the human mind. This section explores three prominent examples of that fragmentation - specifically, fragmentation across environmental media, space and time, and governmental jurisdictions_ — and the continuing debates about an optimal response.

A. Fragmentation across Environmental Media

${ }^{39}$ See U.S. EnVtl. Prot. Agency, OUR BuILt AND NATURAL ENVIRONMENTS 4-8 (2001) (describing rapid growth in recent decades).

${ }^{40}$ See Daniel A. Farber, Law, Sustainability, and the Pursuit of Happiness, 46-53 (UC Berkeley Public Law Research Paper No. 1918204), available at http://ssrn.com/abstract=1918204 (describing how many measures to reduce the environmental impacts of development can improve quality of life); The Economics of Watershed Protection, in THE PRACTICE OF WATERSHED PROTECTION 469 (T. Schueler \& H. Holland eds., 2000) (explaining the economic benefits of measures addressing the water quality impacts of development). Once development occurs, addressing those problems can be much more expensive. See Owen, supra note 2, at 488 (comparing costs).

${ }^{41}$ See generally Buzbee, supra note 13, at 63-74 (describing causes and effects of sprawl). This is not the only reason; consumer preferences, racial biases, poor urban schools, and the economic influence of development interests all also play substantial roles in sprawling development patterns. See generally ANDRES DuANY ET AL., Suburban Nation: THE RiSE OF SPRAWL AND THE DECLINE OF THE AMERICAN DREAM (2000).

${ }^{42}$ See., e.g., Stewart, supra note 9, at 21. 
Environmentalists often cite the so-called "First Law of Ecology: that everything is connected to everything else." 43 That law captures the widely-shared view that human actions have far-reaching consequences, which are not confined to air, water or any other single environmental medium. ${ }^{44}$ Greenacres, for example, would likely impact air quality, water quality, wildlife habitats, energy use, and aesthetics. Regulatory initiatives designed to control these impacts will create their own collateral effects. ${ }^{45}$ The consequences will not merely be environmental, for environmental protection is inextricably intertwined with economics and health. ${ }^{46}$ These interconnections inevitably inspire calls for holistic regulatory approaches that take into account the full range of consequences of any action. ${ }^{47}$

Despite these calls, much of our environmental regulatory system is divided into mediaspecific compartments. Many (though not all ${ }^{48}$ ) of the major federal environmental statutes focus on a single type of pollution or on protecting a single kind of environmental resource. The

${ }^{43}$ See Todd Aagaard, Environmental Harms, Use Conflicts, and Neutral Baselines in Environmental Law, 60 DUKE L.J. 1505, 1517 \& n.40 (2011) (documenting the frequent use of this phrase, and quoting ZYGMUNT J.B. Plater, Robert H. Abrams, William GoldFARB, Robert L. GRAHAM, LiSA HEINZERLING \& DAVID A. WiRTH, ENVIRONMENTAL LAW AND POLICY: NATURE, LAW, AND SOCIETY xxx (3d ed. 2004)).

44 Jonathan Cannon, Environmentalism and the Supreme Court: A Cultural Analysis, 33 ECOLOGY L.Q. 363, 369-70 (2006) ("Environmentalists share a belief that ... human intervention affecting one part of a humannatural system can be expected to have deleterious effects elsewhere in the system.").

${ }^{45}$ See generally RISK VERSUS RisK: TRADEOFFS IN PROTECTING HEALTH AND THE ENVIRONMENT (John D. Graham \& Jonathan Baert Wiener eds., 1995).

46 See President's Council of AdVISORS on SCIENCE AND TECHNOlogy, EXECUtive OfFICE OF THE President, Sustaining EnVIRONMENTAl CAPITAL: Protecting Society AND THE Economy 11-30 (2011) (describing links between environmental protection and human well-being); Robert N. Stavins, Policy Instruments for Climate Change: How Can National Governments Address a Global Problem, 1997 U. CHI. LEGAL F. 293, 29596, 328 (1997) (summarizing the "multifaceted" costs of environmental regulation).

${ }^{47}$ See, e.g., Lakshman Guruswamy, Integrating Thoughtways: Re-Opening of the Environmental Mind?, 1989 WISC. L. REV. 463 (1989).

48 The National Environmental Policy Act (NEPA) provides a significant exception to this generalization, as do its state-law counterparts. 42 U.S.C. $\$ \$ 4331,4332$ (2006); see infra notes 258-267 and accompanying text (discussing NEPA). See also 16 U.S.C. $§ 1455(d)$ (2006) (attempting to provide a framework for using planning to address multiple environmental issues in coastal zones). 
Clean Air Act, Clean Water Act, and ESA provide obvious examples. ${ }^{49}$ Land use regulation is typically addressed not just by separate laws but also by different levels of government. ${ }^{50}$

Consequently, environmental regulation is often highly compartmentalized, with distinct agency offices applying separate statutes to address different environmental consequences of the same underlying action. ${ }^{51}$

This fragmentation is problematic in several ways. First, it can lead to counterproductive regulation. Constraints designed to protect one environmental medium can encourage alternative activities with even worse environmental effects. ${ }^{52}$ Second, fragmentation could generate economically inadvisable regulation, as agencies unwittingly impose controls that create economic costs outweighing environmental benefits. ${ }^{53}$ Both of these potential problems have been exhaustively discussed in legal-academic literature, and avoiding them has been a recurrent justification for cross-media integration. ${ }^{54}$ However, under-regulation may be a greater problem. Many environmental statutes and regulations establish thresholds for regulatory action, and if an activity's impacts do not rise to those thresholds, more lenient regulatory controls apply. ${ }^{55}$ There

${ }^{49}$ See 16 U.S.C. $\S \S 1536,1538$ (2006) (providing protection only to threatened or endangered species); John Charles Kunich, Preserving the Womb of Unknown Species with Hotspots Legislation, 52 HASTINGS L.J. 1149, 1150 (2001) ("The ESA focuses on species, and moves to protect only one species at a time.").

${ }^{50}$ See Solid Waste Agency of N. Cook Cnty. v. U.S. Army Corps of Eng'rs, 531 U.S. 159, 174 (2001) (emphasizing "the States' traditional and primary power over land and water use").

${ }^{51}$ See Stewart, supra note 9, at 21.

${ }^{52}$ See Peter J. Fontaine, EPA's Multimedia Enforcement Strategy: The Struggle to Close the Environmental Compliance Circle, 18 CoLUM. J. ENVTL. L. 31, 33-34 (1993) ("[R]egulatory efforts to control pollutants in one environmental medium often merely transfer them to other environmental media."); STEPHEN BREYER, BREAKING THE VICIOUS CIRCLE 22 (1993) ("[T]he instances are sufficient in number to produce an overall impression of an interprogram, interagency coordination problem.").

${ }^{53}$ See BREYER, supra note 52, at 11 (criticizing administrative "[t]unnel vision"); Sunstein, supra note 8, at 1010, 1027-28.

${ }^{54}$ E.g. Cass R. Sunstein, Cost-Benefit Default Principles, 99 Mich. L. REV. 1651, 1653 (2001) (listing examples); Fontaine, supra note 52, at 33-34.

${ }^{55}$ See, e.g., DANiEl A. FARBER ET Al., CASES AND MATERIALS On ENVIRONMENTAL LaW 547 (8th ed. 2010) (describing the Clean Air Act's distinctions between major and non-major sources); Robin Bravender, EPA Issues Final 'Tailoring' Rule for Greenhouse Gas Emissions, N.Y. TIMES, May 13, 2010 (describing EPA's attempt to exempt smaller sources from greenhouse gas regulations). 
are obvious reasons for adopting such thresholds, ${ }^{56}$ but sometimes an activity with mediaspecific effects that seem tolerable in isolation might seem inadvisable if all of its consequences were considered together. ${ }^{57}$ Greenacres, for example, might not strike a water quality regulator, an air quality regulator, a wetlands regulator, and a land use planner as problematic if each type of impact is considered separately. The collective effect of many impacts, however, might justify major changes to the project, and perhaps even an outright regulatory denial.

For years, environmental policymakers have been aware of these problems, and they have tried to respond in many ways. One category of responses seeks to expand the analytical scope of environmental decision-making. NEPA, for example, attempts to compel more integrative thinking by requiring a single study of a broad range of environmental impacts. ${ }^{58}$ Mandates for cost-benefit analyses, regulatory impact analyses, and paperwork reductions all exemplify a similar impulse toward broadening analytical frames, albeit toward consideration of economic rather than environmental impacts. ${ }^{59}$ Concepts like "sustainable development" reflect the same underlying goal, for sustainable development's basic precept is that economic, social, and environmental systems should be viewed as integrated parts of a larger whole. ${ }^{60}$ The concept of

\footnotetext{
${ }^{56}$ Regulating small sources of environmental degradation can be difficult for administrators, costly for regulated entities, and at odds with a widely shared ideological commitment to regulatory minimalism. See Stack \& Vandenbergh, supra note 4, at 1395-98; Exec. Order No. 13563, 76 Fed Reg. 3821, 3821 (2011) (asserting that our regulatory system "must identify and use the best, most innovative, and least burdensome tools").

57 See, e.g., Fontaine, supra note 52, at 38-46 (describing a facility that for too long escaped vigorous enforcement, largely because different regulators did not realize that violations were part of a larger trend).

${ }^{58}$ See 42 U.S.C. $\$ 4332$ (2006).

${ }^{59}$ See Sunstein, supra note 54, at 1656-63 (summarizing arguments in favor of cost-benefit analysis). For a summary of requirements, see Mark Seidenfeld, A Table of Requirements for Federal Administrative Rulemaking, 27 FLA. ST. U. L. REV. 533 (2000). A less-cited but still important motivation for these requirements is to place procedural hurdles before agencies likely to take undesired actions. See, e.g., Matthew Stephenson, Bureaucratic Decision Costs and Endogenous Agency Expertise, 23 J. L. ECON. \& ORG. 469, 473 (2007).

${ }^{60}$ See J.B. Ruhl, Sustainable Development: A Five-Dimensional Algorithm for Environmental Law, 18 STAN. ENVTL. L.J. 31, 35-36 (1999) ("[S] ustainable development defines all social problems in terms of three parameters - environment, economy, and equity - and projects them in the dimensions of geographic scale and time.").
} 
"ecosystem management," which now pervades the rhetoric of natural resource law, embodies similar ambitions. ${ }^{61}$

Putting these ambitions into practice has not been easy, however. EPA has been the focus of several reform movements, each with the primary goal of addressing multiple pollutants and impacts through consolidated permitting processes. ${ }^{62}$ Those efforts produced a few limited pilot programs and high-profile initiatives, but multi-media permitting processes remain rare. ${ }^{63}$ Cost-benefit analysis is now entrenched in administrative decision-making processes. ${ }^{64}$ But finding enough information to do a good cost-benefit analysis can be very difficult, and observers disagree vehemently about whether those analyses improve or worsen regulatory decision-making. ${ }^{65}$ Sustainable development is now one of the most pervasive buzzphrases in the environmental field, but giving the concept a meaningfully precise definition, let alone transforming it into legal mandates, has not been easy. ${ }^{66}$ The ecosystem management concept

${ }^{61}$ See Harry M. Scheiber, From Science to Law to Politics: An Historical View of the Ecosystem Idea and its Effect on Resource Management, 24 ECOLOGY L.Q. 631 (1997); Lee Breckinridge, Reweaving the Landscape: The Institutional Challenges of Ecosystem Management for Lands in Private Ownership, 19 VT. L. REV. 363, 37077 (1995) (describing ecosystem management concepts, which call for considering multiple resources, geographic and temporal scales, and human and non-human impacts simultaneously).

${ }^{62}$ See, e.g., Krier \& Brownstein, supra note 15, at 119-22; Frances H. Irwin, An Integrated Framework for Preventing Pollution and Protecting the Environment, 22 ENVTL. L. 1, 23-42 (1992) (describing proposals for integrated, multimedia regulation).

${ }^{63}$ See Irwin, supra note 62, at 3-4 (describing the limited achievements of EPA's early efforts); Uwe M. Erling, Approaches to Integrated Pollution Control in the United States and the European Union, 15 TULANE ENVTL. L.J. 1, 4 (2001) ("[E]xamples of a truly holistic multimedia permit can rarely be found").

${ }^{64}$ See John D. Graham, Saving Lives through Administrative Law and Economics, 157 U. PA. L. REV. 395, 401 (2008) ("[T]here is universal consensus that BCA plays a more significant role today than it did a generation ago.").

${ }^{65}$ See Wagner, supra note 16, at 1720-26 (arguing that proponents of cost-benefit analysis make unrealistic assumptions about information availability); Entergy Corp. v. Riverkeeper, Inc., 556 U.S. 208, 237-38 (2009) (Stevens, J. dissenting) (critiquing cost-benefit analysis). For a contrasting view, see Sunstein, supra note 54.

${ }^{66}$ See Daniel C. Esty, A Term's Limits, FoREIGN POL'Y, Sept.-Oct. 2001, at 74 (“'S]ustainable development has largely failed as an organizing principle."). 
has helped produce some concrete results, ${ }^{67}$ but these, too, have a mixed track record of success, and critics have questioned the attainability of ecosystem management almost since the concept's invention. ${ }^{68}$ Looking at the statutory structure of environmental law, the level of integration appears even lower. In the decades since multi-media integration emerged as a widely shared aspiration, Congress has done little to reorient environmental law or to create major new integrating institutions. ${ }^{69}$ Instead, the fragmented statutory system commentators have been criticizing since the 1970 s remains largely unchanged. ${ }^{70}$

The persistence of fragmentation should not be entirely surprising, for any integrative initiative raises significant informational challenges. ${ }^{71}$ To understand the impacts of a project or regulatory action upon just a single environmental medium can be challenging. To understand the impacts of a single project or regulatory action across a range of media, and to understand all of the economic and social consequences of that action, may be much more than a single person or even agency office can accomplish. ${ }^{72}$ That problem may be addressed by pulling more people and offices into the project, but then a coordination challenge partially replaces the initial

${ }^{67}$ The most notable examples are regional, multi-species habitat conservation plans developed under sections nine and ten of the ESA. See Matthew E. Rahn et al., Species Coverage in Multispecies Habitat Conservation Plans: Where's the Science?, 56 BIOSCIENCE 613, 613-14 (2006) (describing the increasing prevalence, and agency promotion, of this approach).

${ }^{68}$ See id.; Alejandro E. Camacho, Can Regulation Evolve? Lessons from a Case Study in Maladaptive Management, 55 UCLA L. REV. 293 (2007) (critiquing the HCP program); Oliver A. Houck, On the Law of Biodiversity and Ecosystem Management, 81 MINN. L. REV. 869 (1997) (questioning whether ecosystem management can fulfill its ambitions).

${ }^{69}$ The most prominent Congressional attempt at integration involves air quality regulation and transportation planning. See Susan Hanson, The Context of Urban Travel: Concepts and Recent Trends, in THE GEOGRAPHY OF URBAN TRANSPORTATION 3, 24-25 (Susan Hanson \& Genevieve Giuliano eds., 3d ed. 2004).

${ }^{70}$ See Peter A. Buchsbaum, Permit Coordination Study by the Lincoln Institute of Land Policy, 36 URBAN LAWYER 191, 193 (2004) (documenting "a general consensus that environmental land use regulation continues to suffer from lack of coordination").

${ }^{71}$ See Krier \& Brownstein, supra note 15, at 125 (arguing that integrated pollution control "assumes intellectual capacities and sources of information that men simply do not possess") (quoting Charles Lindblom, Still Muddling, Not Yet Through, 39 PUB. ADMIN. ReV. 517 (1979).

${ }^{72}$ Some environmental studies still do address an impressive range of environmental consequences. See, e.g., U.S. Dept. Of Interior, Minerals Mgmt. SerV., CaPe Wind Energy Project Final EnVIRONMEntal IMPACT STATEMENT (2009) (providing detailed analysis of a broad range of impacts and alternatives). But that sort of comprehensive analysis is generally very expensive and time-consuming to prepare. 
informational challenge. Fragmentation, for all its dysfunctions, can be administratively efficient, and the continued compartmentalization of environmental law reflects a tacit recognition of this reality. ${ }^{73}$

That reality could change, however. If technology can effectively bolster the human mind's capacity to process information, then adjustment of current fragmentary approaches is appropriate. A key question for the future of environmental law is whether such tools are beginning to emerge.

\section{B. Fragmentation across Space and Time}

Compartmentalization along media-specific lines may be a central challenge for environmental law, but it is by no means the only fragmentation problem. Instead, environmental regulation also routinely confronts decision-makers with the need—often unfulfilled— to think across spatial and temporal scales. ${ }^{74}$

Few environmental problems arise solely from the consequences of a single event, project, or decision. Instead, environmental degradation is often the consequence of many different actions spread across space and time. ${ }^{75}$ Greenacres, for example, might be just one of many developments in its watershed and air basin, and over time the combined effects of those developments for water quality, water supply, and air quality might become significant. ${ }^{76}$ With

\footnotetext{
${ }^{73}$ See Krier \& Brownstein, supra note 15, at 126 ("disjointed incrementalism is necessarily the actual method of policy making in the real world").

${ }^{74}$ See, J.B. Ruhl \& James Salzman, Climate Change, Dead Zones, and Massive Problems in the Administrative State: A Guide for Whittling Away, 98 CAL. L. REV. 59, 64-65 (2010) (identifying these problems as environmental law's greatest challenges); William W. Buzbee, Recognizing the Regulatory Commons: A Theory of Regulatory Gaps, 89 IOWA L. REV. 1, 56 (2003) ("Statutory schemes attempting to protect ambient environmental quality where large harms are created by diverse causes are often unsuccessful.").

${ }^{75}$ See Theobald et al., supra note 4, at 1908-09; Buzbee, supra note 13, at 56-57.

${ }^{76}$ See generally Owen, supra note 2, at 439-45 (explaining how development incrementally degrades water quality); see, e.g., Michael Yarne, Note, Conformity as Catalyst: Environmental Defense Fund v. Environmental Protection Agency, 27 ECOLOGY L.Q. 841, 869-71 (2000) (describing how Atlanta's growth affected air quality).
} 
climate change, the relevant impact could even be global in scale. ${ }^{77}$ The incremental causes of environmental challenges create an obvious need for integrated responses. If policymakers focus only on one event or location, they may not recognize an important threat. ${ }^{78}$ They also may respond inefficiently or inequitably. Some causes might be more cost-effectively redressed than others, but if regulators deal only with one activity at a time, they will miss opportunities to identify those efficiencies. ${ }^{79}$ Conversely, if regulators deal with each contributing source in isolation, they may fail to establish consistent standards or equitable distinctions, leading to claims of unfairness.

For all of these reasons, environmental policymakers for years have sought to broaden the geographic and temporal scope of environmental analysis and regulation. They have done so through several techniques. First, many statutes and regulations call for "cumulative impact analyses." ${ }^{80}$ Such analyses strive to place the potential impacts of a proposed activity in a broader context by considering the effects of other related projects and trends. ${ }^{81}$ Second, many environmental statutes, as well as most states' systems of land use law, call for planning processes,${ }^{82}$ which generally are designed to provide frameworks for decisions on individual

\footnotetext{
${ }^{77}$ See Stack \& Vandenbergh, supra note 4, at 1402-12.

${ }^{78}$ See U.S. EnVtl. Prot. Agency, OfFice of Federal Activities, Consideration of Cumulative IMPACTS IN EPA REVIEW OF NEPA DOCUMENTS 1 (1999) ("The combined, incremental effects of human activity, referred to as cumulative impacts, pose a serious threat to the environment.").

${ }^{79}$ See Ackerman \& Stewart, supra note 16, at 1335 (stressing these disparities in cost, though in an argument for market-based schemes).

${ }^{80}$ See, e.g., COUNCIL ON ENVTL. QUALITY, CONSIDERING CUMULATIVE IMPACTS UNDER THE NATIONAL ENVIRONMENTAL POLICY ACT (1997); U.S. Fish \& WILDLIFE SERV. \& NAT’L MARINE FISHERIES SERV., ENDANGERED SPECIES ACT CONSULTATION HANDBOOK 4-31 to 4-33 (1998) (providing guidance for cumulative impact analyses).

${ }^{81}$ See EnVTL. PROT. AgENCY, supra note 78, at 2.

${ }^{82}$ See, e.g., 42 U.S.C. $\$ 7410$ (2006) (air quality planning); 33 U.S.C. § 1313(e) (water quality planning); 16 U.S.C. $§ 1533(\mathrm{f})$ (requiring recovery planning for threatened and endangered species); 16 U.S.C. $§ 1604$ (forest planning); 43 U.S.C. § 1712 (requiring "land use plans"); Patricia E. Salkin \& Amy Lavine, Regional Foodsheds: Are Our Local Zoning and Land Use Regulations Healthy?, 22 FordHAM ENVTL. L. REV. 599, 611 (2011) ("Most state statutes require that zoning regulations be developed and implemented in accordance with a comprehensive land use plan....").
} 
projects or regulatory initiatives. ${ }^{83}$ Often planning and cumulative impact analysis are tightly coupled, with programmatic environmental analysis of the plan providing a broader review and enabling studies for individual projects to focus on site-specific consequences. ${ }^{84}$

More recently, environmental policymakers have sought spatial and temporal integration through trading schemes. In their earliest and simplest form, these trading schemes expanded the geographic focus of regulation from individual smokestacks to facilities as a whole, and allowed regulated plants to compensate for emissions increases in one location through reductions elsewhere. ${ }^{85}$ The appeal of this approach was straightforward: regulators would still obtain their desired emission limitations, and regulated entities could find the cheapest place to put those limitations into effect. ${ }^{86}$ Subsequent initiatives, like the acid rain program developed as part of the 1990 Clean Air Act Amendments, expanded the geographic scope to allow trading between different plants, sometimes over large geographic areas. ${ }^{87}$ They also allowed "banking," which means trading emission reductions in the present for emission increases in the future. ${ }^{88}$ Such spatial and temporal trading programs are now central features of environmental law. ${ }^{89}$

${ }^{83}$ See, e.g., Ohio Forestry Ass'n v. Sierra Club, 523 U.S. 726, 729-30 (1998) (describing the relationship between a forest management plan and subsequent site-specific decisions).

${ }^{84}$ See, e.g., V. Alaric Sample, Assessing Cumulative Environmental Impacts: The Case of National Forest Planning, 21 ENVTL. L. 839, 843 (1991).

${ }^{85}$ See Jody Freeman, The Story of Chevron: Environmental Law and Administrative Discretion, in ENVIRONMENTAL LAW STORIES 172, 178-84 (Richard J. Lazarus \& Oliver A. Houck eds. 2005) (describing early efforts).

${ }^{86}$ See id. at $179-80$.

${ }^{87}$ See Byron Swift, How Environmental Laws Work: An Analysis of the Utility Sector's Response to Regulation of Nitrogen Oxides and Sulfur Dioxide Under the Clean Air Act, 14 TULANE ENVTL. L.J. 309, $319-22$ (2001).

${ }^{88}$ See Robert W. Hahn \& Gordon L. Hester, Marketable Permits: Lessons for Theory and Practice, 16 ECOLOGY L.Q. 361, 368 (1989).

${ }^{89}$ See James Salzman \& J.B. Ruhl, Currencies and the Commodification of Environmental Law, 53 STAN. L.REV. 607, 609 (2000) (describing "growing interest in market-based mechanisms"); Tom Tietenberg, Tradable Permits in Theory and Practice, in MOVIng TO MARKETS In ENVIRONMENTAL REGULATION: LESSONS FROM TWENTY YEARS OF EXPERIENCE 63 (Jody Freeman \& Charles D. Kolstad eds., 2007) (hereinafter "MovING TO MARKETS") (describing applications). 
Like efforts at multi-media integration, these temporal and spatial integration efforts have faced challenges. For planning and cumulative impact analysis, the core problem is simple: doing either well requires gathering and processing a tremendous amount of information. ${ }^{90}$ If many different governmental and private actors contribute to an environmental problem, just identifying all the activities that might contribute to an environmental problem can require a significant effort. ${ }^{91}$ Predicting the collective consequences of those many different activities can be even more difficult. Environmental systems are often complex and dynamic, with synergistic effects and feedback loops complicating efforts at prediction. ${ }^{92}$ Consequently, cumulative impact analyses and comprehensive plans, while easy to call for, are often difficult to complete. The environmental law literature is filled with accounts of plans gone wrong, ${ }^{93}$ and many critics have argued that environmental planning creates unrealistic information demands and therefore is doomed to failure. ${ }^{94}$ Similarly, most experienced environmental practitioners can recount tales of cumulative impact analyses that were cursory at best. ${ }^{95}$

Trading schemes might seem to obviate some of these informational problems, for a market-based system theoretically can succeed without any single entity possessing synoptic knowledge of the activities at issue. ${ }^{96}$ In practice, however, trading schemes raise their own informational challenges. The traded things rarely are fungible; a natural wetland to be

\footnotetext{
${ }^{90}$ See Oliver A. Houck, The Clean Water Act TMDL Program: LaW, POlicy, and IMPLEMENTATion 63 (2nd ed. 2002).

${ }^{91}$ See, e.g., Fine \& Owen, supra note 28, at 953-55 (describing the information-gathering necessary to support air quality modeling).

${ }^{92}$ See Ruhl \& Salzman, supra note 74, at 88-92 (describing these dynamics).

${ }^{93}$ See, e.g., Fine \& Owen, supra note 28, at 962-64 (describing unsuccessful air quality planning); Arnold W. Reitze, Jr., Air Quality Protection Using State Implementation Plans - Thirty-Seven Years of Increasing Complexity, 15 VILL. ENVTL. L.J. 209, 357-65 (2004) (calling state implementation planning a "failure").

${ }^{94}$ E.g. HoucK, supra note 90, at 257 (2nd ed. 2002) (describing planning-based approaches as "chronically difficult in their science and their political science").

${ }^{95}$ See EnVTL. PROT. AGENCY, supra note 78, at 1 ("Cumulative impacts... are not often fully addressed in NEPA documents").

${ }^{96}$ See Hahn \& Hester, supra note 88, at 361-62 (identifying markets as an antidote to informational challenges).
} 
destroyed to allow development may be far more ecologically valuable than a replacement wetland constructed elsewhere. A recurring concern about environmental trading schemes therefore is that the trades will be chronically uneven, with the environment on the losing end, unless regulators review each trade. ${ }^{97}$ However, providing that oversight can be a substantial task, particularly if, as is often the case, the trading scheme involves many actors and actions. ${ }^{98}$ Consequently, administering an environmentally protective trading scheme is often an information-intensive exercise, which elevates transaction costs and can limit efficiency. ${ }^{99}$ Partly for these reasons, many commentators remain skeptical about the utility of environmental trading schemes. ${ }^{100}$

As with debates over multi-media integration, these debates over spatial and temporal integration remain unresolved. ${ }^{101}$ In practice, environmental law retains a mix of all of these approaches, with technology-based systems, trading systems, and planning systems often overlapping in ways that defy easy categorization, and with the proper balance among those approaches still subject to vigorous discussion. That appropriate balance also could change. Our

${ }^{97}$ See Salzman \& Ruhl, supra note 89, at 622-30 (describing the pervasiveness of trading in non-fungible things); see, e.g., Tietenberg, supra note 89, at 87 (describing traders' lack of incentive to ensure environmental fungibility); Eric Freyfogle, Water Rights and the Common Wealth, 26 ENVTL. L. 27, 31-33 (1996) (describing the importance of context for water use). But see Holly Doremus and W. Michael Hanemann, Of Babies and Bathwater: Why the Clean Air Act's Cooperative Federalism Framework is Useful for Addressing Climate Change, 50 ARIZ. L. REV. 799, 803 (2008) (“CO $\mathrm{CO}_{2}$ emissions are extraordinarily fungible....").

${ }^{98}$ See Lesley K. McAllister, The Enforcement Challenge of Cap-and-Trade Regulation, 40 ENVTL. L. 1195, 1196-1202 (2011); Doremus \& Hanemann, supra note 97, at 814-16.

${ }^{99}$ See James Salzman \& J.B. Ruhl, "No Net Loss": Instrument Choice in Wetlands Protection, in Moving TO MARKETS, supra note 89, at 338-39 (discussing how this tension affects wetlands trading). For air pollution trading, some studies have concluded that informational burdens are more manageable. See Winston Harrington \& Richard D. Morganstern, International Experience with Competing Approaches to Environmental Policy: Results from Six Paired Cases, in MOVING TO MARKETS, supra note 89, at 95, 117-18.

${ }^{100}$ See, e.g., Salzman \& Ruhl, supra note 89 (questioning the effectiveness of markets for habitat protection); Center for Race, Poverty, and the Environment, Climate Justice Campaign, at http://www.crpeej.org/crpe/index.php/campaigns/climate-justice (last visited November 29, 2011) (calling trading systems "ineffective").

${ }^{101}$ See generally Moving to Markets, supra note 89 (containing multiple views of markets, some complementary and others less so). For disparate views on environmental planning, compare HouCK, supra note 90 (criticizing planning) with THE White House COUNCIL ON ENVTL. QuAliTY, FINAL RECOMMENDATIONS OF THE INTERAGENCY OCEAN POLICY TASK FORCE (2010) (calling for a massive new planning initiative). 
capacity for spatially and temporally integrative decision-making is limited largely by our capability of processing information, and if technology is enhancing that capacity, then integrative regulatory approaches should be increasingly viable.

C. Jurisdictional Fragmentation

These challenges of spatial, temporal, and media-based fragmentation are intertwined with challenges of institutional fragmentation. Most major environmental problems implicate federal, state, and local regulatory authority. ${ }^{102}$ They also affect the interests of private businesses, advocacy groups, and individuals. ${ }^{103}$ Often the knowledge necessary to understand environmental problems is dispersed throughout these complex institutional landscapes, and solving environmental problems is impossible without coordination across both jurisdictional and public-private boundaries. ${ }^{104}$

This dispersal of knowledge and authority creates its own set of challenges. If multiple agencies hold responsibility over different aspects or effects of the same activity, they may act at cross-purposes. Local land use regulators, for example, might pass large-lot zoning requirements designed to preserve aesthetic qualities (or, more insidiously, socio-economic segregation), ${ }^{105}$ yet those requirements can spread development across more of the landscape, creating perverse outcomes for water quality protection, habitat protection, air quality, and energy use. ${ }^{106}$ Energy regulators might try to promote energy-efficient power plant cooling systems even as water

\footnotetext{
102 See Lazarus, supra note 7, at 35; see, e.g., Robin Kundis Craig, Climate Change, Regulatory Fragmentation, and Water Triage, 79 U. COLO. L. REV. 825, 834-69 (2008).

${ }^{103}$ See generally Jody Freeman, The Private Role in Public Governance, 75 N.Y.U. L. REV. 543 (2000).

104 See Freeman \& Farber, supra note 11, at 797-98.

105 See Lawrence Gene Sager, Tight Little Islands: Exclusionary Zoning, Equal Protection, and the Indigent, 21 STAN. L. REV. 767, 781 (1969).

${ }^{106}$ See Peter Whoriskey, Density Limits Only Add to Sprawl: Large Lots Eat up Area Countryside, WASHINGTON Post, March 9, 2003, at A1;
} 
quality and fishery regulators complain of impacts upon aquatic systems. ${ }^{107}$ Regulators also may not act at all. An upstream or upwind state, for example, may have little incentive to control pollution emissions. ${ }^{108}$ Even where multiple jurisdictions share the burden of an environmental problem, a "regulatory commons" dynamic, in which no agency has enough incentive to act, can preclude effective responses. ${ }^{109}$ Combinations of inaction and conflicting action also may arise. When they do, as the bungled response to Hurricane Katrina illustrates, the result can be a costly debacle. ${ }^{110}$ Addressing these problems of institutional complexity therefore remains another central challenge of environmental law.

These problems are centrally important to debates about environmental federalism. Our government is by design a system of divided authority, with federal, state, and local authorities and a robust private sector all theoretically playing important roles. ${ }^{111}$ But those different institutions must coordinate and may come into conflict, creating questions about who holds decision-making authority and where jurisdictional boundaries should lie. ${ }^{12}$ For years, those questions have formed one of environmental law's key battlegrounds, with jurists and commentators asserting dramatically different views about how our federalist system should face the challenges of jurisdictional fragmentation. ${ }^{113}$

${ }^{107}$ See Entergy v. Riverkeeper, Inc., 556 U.S. 208, 216 (2009) (noting the energy costs of installing cooling systems with lower water quality impacts).

108 See Daniel C. Esty, Toward Optimal Environmental Governance, 74 N.Y.U. L. REV. 1495, 1543 (1999) ([P]rogress on acid rain would likely never have been made as long as the issue were left to state level initiative....").

109 See Buzbee, supra note 74 , at 6.

${ }^{110}$ See Erin Ryan, Federalism and the Tug of War Within: Seeking Checks and Balance in the Interjurisdictional Gray Area, 66 MD. L. REV. 503, 518-36 (2007). liberty).

${ }^{111}$ See Bond v. U.S., 131 S.Ct. 2355, 2364-65 _ U.S. __ (2011) (arguing that federalism protects political

112 See generally William W. Buzbee, Interaction's Promise: Preemption Policy Shifts, Risk Regulation, and Experimentalism Lessons, 57 EMORY L.J. 145 (2007).

${ }^{113}$ See infra notes 303-313 and accompanying text. 
These challenges also raise important, and closely related, questions about how to encourage effective coordination in complicated institutional landscapes. ${ }^{114}$ In response to these questions, many legal scholars have explored what makes interjurisdictional coordination succeed. ${ }^{115}$ They have focused primarily on bureaucratic structures, divisions of authority, and measures for public participation. ${ }^{116}$ Such questions of power and procedure obviously are very important. But an equally consequential, and largely unexamined, set of questions involves the substance of interjurisdictional communications. Different agencies have different goals and cultures, rely on different data, and use different methods and terminology for communication. ${ }^{117}$ Private firms and public participants often bring their own divergent perspectives and knowledge to the table. Finding common languages for these participants to pool information, develop shared understanding, and identify areas where their goals coincide or conflict therefore is crucially important. A key question for environmental law, then, is whether such communication tools exist, or are beginning to emerge, and how their emergence (or absence) should change approaches to environmental regulation.

D. Intertwining Systems of Fragmentation

These problems of fragmentation among media, within space and time, and across jurisdictions often occur in combination. With Greenacres, for example, impacts on different environmental media would be regulated not just by different statutes but also by different

\footnotetext{
114 See Ruhl \& Salzman, supra note 74, at 64-65 (explaining the prevalence of these challenges).

115 See, e.g., Freeman \& Farber, supra note 11; Ruhl \& Salzman, supra note 74, at 109-19; Holly Doremus, CALFED and the Quest for Optimal Institutional Fragmentation, 12 ENVT'L SCI. AND POL'Y 729 (2009).

116 See, e.g., Freeman \& Farber, supra note 11 (offering "modular regulation" as a solution to coordination challenges); Ruhl \& Salzman, supra note 74, at 109-19 (promoting solutions based on "weak ties networks").

${ }^{117}$ See generally Eric Biber, Which Science? Whose Science? How Scientific Disciplines Can Shape Environmental Law, __ U. CHI. L. REV. __ (forthcoming 2012) (exploring these differences).
} 
agencies, some local, some state, and some federal. ${ }^{118}$ The impacts also would likely spill across municipal, state, and sometimes even national boundaries. ${ }^{119}$ But jurisdictional boundaries and cultural differences will create barriers to coordination; a volunteer local planning board will likely frame issues quite differently from a federal agency dominated by wildlife biologists or air quality scientists and engineers. ${ }^{120}$ The common result is what policy analysts refer to as a "wicked" problem, in which simply defining the scope of the regulatory challenge, let alone resolving it, is very difficult. ${ }^{121}$

In practice, those difficulties often seem insurmountable. Rather than coordinate effectively, state and federal regulators may initially leave oversight of Greenacres, and many other developments like it, almost entirely under local control. ${ }^{122}$ Local regulators, though perhaps generally aware that development is connected to habitat protection, water supply, water quality, air quality, and a variety of other broad environmental trends, may have little idea how to translate those broad concerns into site-specific regulatory controls, let alone how to coordinate with other localities in developing an effective response, and therefore may do nothing at all. ${ }^{123}$ Often, it is only when development patterns clearly become incompatible with

\footnotetext{
118 See Buzbee, supra note 13, at 91 (describing the dispersion of authority over sprawl's causes and effects).

119 See, e.g., U.S. EnVtl. Prot. Agency Region 3 et Al., Chesapeake BAy Total MaXimum DaILY LOAD FOR NITROGEN, PHOSPHORUS AND SEDIMENT ES-3 (2010) (describing sources of impairment of Chesapeake Bay); W.R. Stockwell et al., Ozone Formation, Destruction and Exposure in Europe and the United States, in FOREST DECLINE AND OZONE 1, 1 (Heinrich Sanderman et al. eds, 1997) (describing regional ozone transport); Hari M. Osofsky, Is Climate Change “International”? Litigation's Diagonal Regulatory Role, 49 VA. J. INT'L L. 585 (2009) (exploring the multiscalar dimensions of climate change).

${ }^{120} \mathrm{I}$ base this claim on experience with local boards and with agency scientists and engineers. The differences in expertise and perspective are often profound.

${ }^{121}$ See Richard J. Lazarus, Super Wicked Problems and Climate Change: Restraining the Present to Liberate the Future, 94 CORNELL L. REV. 1153, 1159-60 (2009).

${ }^{122}$ See Buzbee, supra note 13, at 91 (noting presumptions favoring local control).

123 Their inaction also may be motivated by the local political influence of pro-development entities and by collective action problems. See id. at 77-91 (exploring the political dynamics of sprawl). However, in working with local governments, I have often found genuine interest in protecting environmental quality but little understanding about how to connect those overall goals to specific land use decisions.
} 
state or federal environmental quality mandates that local, state, and federal entities attempt to coordinate or resign themselves to do battle. ${ }^{124}$ By that time, proactive solutions are unlikely to be available. The remedies instead will be expensive, if they are implemented at all, and both local autonomy and environmental quality will suffer. This dysfunctional dynamic creates an acute need to find a better way.

\section{The EMERGENT GeOCODED AgE}

Forty years ago, when environmental law began developing its current responses to these challenges of fragmentation, the term "geographic information systems" was hardly ever used. ${ }^{125}$ Computer-based modeling ${ }^{126}$ was in its infancy, and the processing capacity of computer systems was orders of magnitude lower than it is today. ${ }^{127}$ Researchers in many fields used statistics, but regression analyses of large, multivariable data sets were enormously time-consuming. ${ }^{128}$ Consequently, many environmental sciences were very different than they are now. Ecologists may have believed that "everything was connected to everything else," but they had limited tools to understand how.

${ }^{124}$ See, e.g., Owen, supra note 2, at 480-83, 502-03 (describing innovative but belated water quality protection efforts); Nat'l Assoc. of Home Builders v. San Joaquin Valley Unified Air Pollution Control Dist., 627 F.3d 730, 731-32 (9th Cir. 2010) (discussing a rule, adopted only after years in non-attainment status, designed to control ozone precursor emissions from development); supra notes 30-38 and accompanying text (discussing the Atlanta region).

${ }^{125}$ Prototypes of modern GISs were emerging but not in widespread use. See KeITH C. ClaRKE, GETTING STARTED WITH GEOGRAPHIC INFORMATION SYSTEMS 8-9 (1999) (describing the evolution of GIS).

${ }^{126}$ Environmental researchers understand the term "model" in a variety of ways, but recent report defines a model as "a simplification of reality that is constructed to gain insight into select attributes of a particular physical, biological, economic, or social system.” COMM. ON MODELS IN THE REGULATORY DECISION PROCESS, NAT'L RESEARCH COUNCIL, MODELS IN ENVIRONMENTAL REGULATORY DECISION MAKING 31 (2007).

${ }^{127}$ See John O. McGinnis, Laws for Learning in an Age of Acceleration, 53 WM. \& MARY L. REV. 305, 311-14 (2011) (describing exponential growth in computing power).

128 See John O. McGinnis, Age of the Empirical, 137 POL'Y REV. 47, 49 (2006) (“One University of Chicago social scientist is said to have taken the entire summer to run a regression on a mainframe computer 40 years ago. Now researchers can run scores of regressions on their laptops in a few hours."). 
In the past four decades, however, those tools have evolved, and this Part turns from the dysfunctions of fragmented regulation to the co-evolution of spatial analysis and environmental research. The discussion is necessarily quite general, and it covers only a small subset of the ways in which spatial analysis now is used. Nevertheless, even that subset illustrates an important point: spatial analysis has important implications for any field, like environmental law, that depends upon information about the physical or human environment. ${ }^{129}$

\section{A. The Emergence of Quantitative Spatial Analysis}

In the mid-nineteenth century, London suffered a series of cholera outbreaks. ${ }^{130}$ The cause of cholera then was unknown; a leading theory postulated that the primary disease vector was a "miasma" emanating from an infected person's body. ${ }^{131}$ However, John Snow, a young doctor, suspected that the disease instead was transferred through faecal-oral contact. ${ }^{132}$ To test his hypothesis, Snow gathered and mapped data on cholera deaths during a particularly virulent outbreak in London's Broad Street neighborhood. ${ }^{133}$ His research showed, and subsequent studies confirmed, that the outbreak could be traced back to the contamination of a single well. ${ }^{134}$ Snow persuaded the city to close the well, ending the epidemic, and he eventually earned recognition as one of the founding figures of epidemiology. ${ }^{135}$ By coupling a database with a map — in other words, by using spatial analysis — Snow was able to solve a problem that previously had defied understanding, to save hundreds of lives, and to help redefine the

\footnotetext{
${ }^{129}$ See Cary Coglianese et al., Seeking Truth for Power: Informational Strategy and Regulatory Policymaking, 89 MINN. L. REV. 277, 277 (2004) ("Information is the lifeblood of regulatory policy.").

${ }^{130}$ See S.W.B. Nelson, Pioneers in infection control: John Snow, Henry Whitehead, the Broad Street pump, and the beginnings of geographical epidemiology, 64 J. HOSP. INFECTION 210, 211 (2006).

${ }^{131} I d$.

${ }^{132} \mathrm{Id}$.

${ }^{133}$ Id. at 213-14; see Paul Bingham et al., John Snow, William Farr and the 1849 outbreak of cholera that affected London: a reworking of the data highlights the importance of the water supply, 118 PUB. HEALTH 387 (2004) (using linear regression analysis to validate Snow's conclusions).

134 Nelson, supra note 130, at 213-14.

${ }^{135}$ Id. at 215-16.
} 
methodologies of an emerging research field. In the decades since, and particularly in the last forty years, researchers have turned Snow's methodology into one of the predominant research and planning practices in many fields. That transition has been supported by several technological shifts, each of which helped transform spatial analysis into a tool more powerful than John Snow probably could have imagined.

One shift was an enormous expansion in societal capacity to gather spatially coded data. Remote sensing, which uses satellites to document landscape features like elevation or infrared radiation, now allows researchers to quickly gather information about the distribution of landscape features and to track changes in land cover. ${ }^{136}$ Satellite photography serves similar purposes, and is particularly useful for mapping land use. ${ }^{137}$ With the widespread availability of global position systems (GPS), data gathered through more traditional technologies also can be geographically coded. ${ }^{138}$ Census data, for example, now are linked to specific geographic locations, ${ }^{139}$ as are many of the data sets gathered through hundreds of ongoing environmental monitoring programs. ${ }^{140}$ Funding has both spurred and followed these technological advances. The National Science Foundation and other major supporters of scientific research continue to call for, and support, major initiatives focused on gathering spatially coded data. ${ }^{141}$

136 See HAINING, supra note 18, at 92 ("Satellites are an important source of environmental data.").

137 See MichaEl N. DEMERS, FundAMENTALS OF GEOGRAPHIC INFORMATION SySTEMS 41-42 (2nd ed. 2000) (describing uses).

${ }^{138}$ See id. at 37-39 (noting that "[m]any data are still observed through ground survey methods" and explaining how GPSs can help geocode those data);

${ }^{139}$ See U.S. Census Bureau, Data Access Tools, http://www.census.gov/main/www/access.html (last visited December 2, 2011) (providing access to data and to multiple mapping tools).

${ }^{140}$ E.g. U.S. Envtl. Prot. Agency, Geospatial Data Downloads, http://www.epa.gov/waters/data/downloads.html (last visited December 2, 2011) (linking to sources of spatially coded water quality data); DEMERS, supra note 137, at 39 (describing the use radiotelemetry to track animal movements).

${ }^{141}$ See, e.g., NEON, at http://www.neoninc.org/. 
Computing advances also improved the availability of those data. ${ }^{142}$ Database programs now allow enormous datasets to be stored, searched, and transferred. In the 1980s, the emergence of personal computers allowed broader access to these databases; no longer did users need to access a larger mainframe. ${ }^{143}$ In the 1990s and 2000s, with the enormous growth of internet use, many databases became available on-line. ${ }^{144}$ These advances have not eliminated data shortages; despite improved technologies, data gaps remain persistent. ${ }^{145}$ But the amount of spatial environmental data available for analysis has vastly increased and continues to grow, ${ }^{146}$ and calls for additional increases are widespread. ${ }^{147}$

142 See Malczewski, supra note 18 , at 9.

${ }^{143}$ See ClARKE, supra note 125, at 9; Malczewski, supra note 18, at 10 (emphasizing the importance of "low-cost mini and PC platforms."). This evolution continues to unfold. See John D. Landis, A Brave and Better World? The iPad and the Future of Planning, PlAnETIZEN (Feb. 7, 2012, at 2:00 P.M.), http://www.planetizen.com/node/54337.

144 See Malczewski, supra note 18, at 12 ("All major GIS vendors are developing procedures for WWWbased access to data and models developed with their software."). Government entities often play a major role in disseminating spatial data. See Peter M. Flannery, How to Pry with Maps: The Fourth Amendment Privacy Implications of Governmental Wetland Geographic Information Systems (GIS), 29 RUTGERS COMPUTER \& TECH. L.J. 447, 454-55 (2003) (listing governmental sources). However, datasets have value, and both private and some governmental entities therefore have incentives to make data available only for a fee. See Allyson Phillips, A Portal to Reliable Real Estate Data or A Door to Nowhere? A Look at How State and Local Dissemination Policies Have Impacted the Development of the National Spatial Data Infrastructure and Geospatial One-Stop Portal, 34 REAL EsT. L.J. 9, 9-10, 26 (2005); Amy Wilson Morris \& Adena R. Rissman, Public Access to Information on Private Land Conservation: Tracking Conservation Easements, 2009 WISC. L. REV. 1237, 1242.

145 See generally Eric Biber, The Problem of Environmental Monitoring, 83 U. COLO. L. REV. 1 (2012).

146 See Malczewski, supra note 18, at 12 (describing "an explosion of digital data").

${ }^{147}$ See, e.g., Phillips, supra note 144, at 36-40 (describing efforts to create a national "Geospatial One-Stop Portal"). 
Figure 1: Adding Datalayers. From Geographic Information Systems, at

http://rst.gsfc.nasa.gov/Sect15/Sect15_1.html.

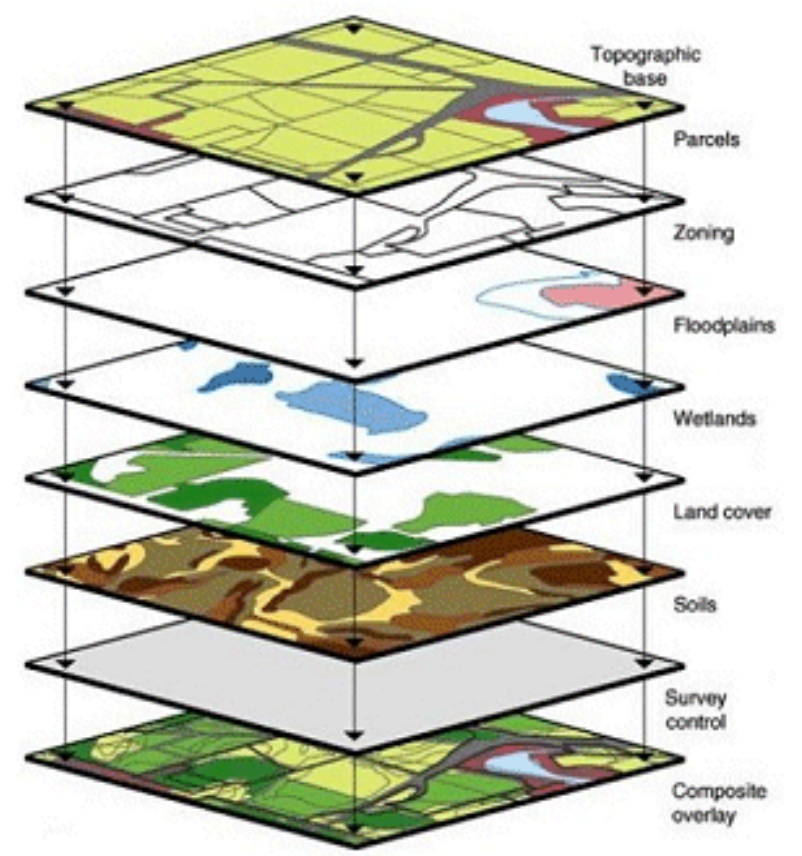

Improved technology also has offered new ways to convey the information stored in these growing databases. Using maps to convey data is nothing new; traditional maps convey information about where roads, landforms, and jurisdictional boundaries are located. ${ }^{148}$ But traditional maps are unwieldy in some ways. Put too much data on the map and it becomes cluttered; put too little, and the map does not provide the information a user needs. Scale is a challenge; traditional paper maps do not allow a

user to zoom in or out. The static nature of paper maps also presents difficulties. Landscapes evolve, but paper maps, once printed, do not.

Newer technologies can address these problems in a variety of ways. Perhaps the most prevalent is to integrate graphical representations of many individual "data layers," with each layer describing a particular set of geographic features. To build a map, a user can select whatever series of datalayers serves her present purpose while leaving out any extraneous information, and can do so at her preferred scale. Once the datalayers have been created, the process is fast and increasingly user-friendly; with just a few mouse clicks the planner can create a customized map. ${ }^{149}$ Indeed, many GIS platforms allow internet users - even users with very

148 See CLARKE, supra note 125 , at 7.

149 See Malczewski, supra note 18, at 12 ("The common interface tools like on-screen 'buttons' and dropdown menus... can be understood quickly and easily with the result that GIS can tap into the growing market of untrained users."). I have watched planners do this, with results projected on a screen and participants suggesting changes. The ease with which maps can be customized is remarkable. 
little technological sophistication - to create and customize their own maps. ${ }^{150}$ Datalayers also can be updated, so a map reflects the most recent version of the underlying databases, and maps themselves can be animated to show changes over time. ${ }^{151}$ In short, in a variety of ways, computers can turn maps into more versatile, dynamic, and accessible tools for conveying information.

Technological advances also facilitate more sophisticated quantitative analyses of that information. For generations, economists, environmental scientists, and other researchers have used statistical analysis as an important research tool. Their statistical work, however, was once limited by the storage and processing capacity of the human brain. Advances in computer processing capacity have dramatically changed the game. ${ }^{152}$ Computers now are capable of running millions of calculations in relatively short periods of time. ${ }^{153}$ Concurrent with those advances, GIS programmers have developed multiple ways to mathematically represent the geography of features in their databases, and thus have allowed statistical analyses of the spatial relationships among data points. ${ }^{154}$ With these advances, analysts now can analyze enormous

${ }^{150}$ See, e.g., Office of Geographic Mapping, Online Mapping, http://www.mass.gov/mgis/mapping.htm (last visited December 2, 2011) (linking to mapping applications).

${ }^{151}$ See, e.g., Cindy Bell et al., Dynamic Mapping of Urban Regions: Growth of the San Francisco/Sacramento Region, http://landcover.usgs.gov/urban/umap/pubs/urisa_cb.php (last visited January 23, 2012) (describing and linking to an animated map).

${ }^{152}$ See Malczewski, supra note 18, at 11 (explaining how computing power spurred GIS development); Robert A. Pietrowsky, Foreword, in CONVERGING WATERS: INTEGRATING COLLABORATIVE MODELING WITH PARTICIPATORY PROCESSES TO MAKE WATER RESOURCES DECISIONS vi (Lisa Bourget ed., 2011) (hereinafter "CONVERGING WATERS") ("technology has transformed what is possible").

${ }^{153}$ See McGinniss, supra note 128 , at 49.

${ }^{154}$ See CLARKE, supra note 125, at 9 (describing the emergence of these techniques). 
spatially coded datasets to detect trends, correlations, and causes that even a few decades ago would have eluded discovery. ${ }^{155}$

Partly because of these increases in computing capacity, spatial analysis has become inextricably linked with environmental managers' large and growing dependence upon computer-based simulation modeling. From climate change to wildlife management, models now pervade almost every sub-field of environmental decision-making. ${ }^{156}$ Many of those models draw upon spatial data, and many produce spatially explicit outputs — which then can be used as input data by other models. ${ }^{157}$ Consequently, spatially explicit modeling has become a pervasive, and often indispensable, part of environmental management and research. At their best, these models add a whole new power to spatial analysis. ${ }^{158}$ Rather than just delineating the location of current landscape features, or, like John Snow's research, teasing out causal relationships based on data about past events, they allow environmental managers to offer spatially explicit representations of possible futures. ${ }^{159}$

These changes represent more than just the emergence of a new set of technological tools. Improvements in hardware, software, and remote sensing technology would have only

${ }^{155}$ See Naomi Oreskes, Why Believe a Computer? Models, Measures, and Meaning in the Natural World, in The EARTH ARound Us: MaINTAINING A Livable Planet 70, 73 (Jill S. Schneiderman ed., 2000) ("[F[ast, inexpensive computers... enable us to study problems that might otherwise remain intractable."); see, e.g., Kevin Costas et al., A case-control study of childhood leukemia in Woburn, Massachusetts: the relationship between leukemia incidence and exposure to public drinking water, 300 THE SCIENCE OF THE TOTAL ENVIRONMENT 23, 24 (2002) (explaining how spatial analysis allowed researches to conclusively link a leukemia outbreak (famously chronicled by Jonathan Harr's bestseller A Civil Action) to groundwater contamination).

${ }^{156}$ See Wagner et al., supra note 28, at 294 (describing "extraordinary influence on environmental policy"); see, e.g., Fine \& Owen, supra note 28 (describing the use of modeling in air quality regulation); Robert L. Glicksman, Bridging Data Gaps through Modeling and Evaluation of Surrogates: Use of the Best Available Science to Protect Biological Diversity Under the National Forest Management Act, 83 IND. L.J. 465 (2008); Daniel A. Farber, Modeling Climate Change and its Impacts: Law, Policy, and Science, 86 TEX. L. REV. 1655 (2008).

${ }^{157}$ See generally RALF SEPPELt, COMPUTER-BASED ENVIRONMENTAL MANAGEMENT 21-22 (2003); Fine \& Owen, supra note 28, at $928 \mathrm{n} .138$ (describing air quality modelers' use of independently modeled population and economic growth projections as input data).

${ }^{158}$ See Fine \& Owen, supra note 28, at 904, 913 (discussing benefits of modeling).

${ }^{159}$ See infra Part III (describing applications). 
modest utility if not accompanied by an associated body of theory. Researchers now refer to this field as "geographic information science," and it has its own professors, journals, conferences, blogs, and even sub-fields. ${ }^{160}$ Many researchers who would not define themselves as geographic information scientists also consider spatial analysis techniques to be centrally important to their discipline. ${ }^{161}$ Geography and planning, for example, are as reliant on spatial analysis as lawyers are upon web-based research systems like Lexis and Westlaw. In ecology, environmental economics, and archaeology, spatial analysis also plays a central role. ${ }^{162}$ Most universities offer courses in spatial analysis, and many offer GIS certificates. ${ }^{163}$ Their graduates use those skills for city planning departments, consulting firms, and state and federal agency offices throughout the country. ${ }^{164}$ A new academic and professional discipline has emerged, with capabilities largely unheard of when our system of environmental law was formed, and with influence extending throughout — indeed, well beyond — the environmental field.

\section{B. Spatial Analysis and Public Participation}

While technological advances allow spatial analysts to do remarkable things, those advances are not an unqualified good. Any increase in the technological sophistication of decision-making creates the threat of overreliance on technology at the expense of common sense. ${ }^{165}$ Quantitative modes of decision-making almost invariably involve oversimplifications, subjective judgments, and data of uneven quality, yet the apparent precision of the numeric

${ }^{160}$ See Malczewski, supra note 18, at 6 (describing this “emerging discipline”); Renee Sieber, Public Participation Geographic Information Systems: A Literature Review and Framework, 96 ANNALS OF THE ASSOC. OF AM. GEOGRAPHERS 491 (2006).

${ }^{161}$ J.T. Coppock \& D.W. Rhind, The History of GIS, in GEOGRAPHIC INFORMATION SYSTEMS 21, 22 (Paul A. Longley ed., 1st ed. 1991).

${ }^{162}$ Disciplines, GIS.COM, http://www.gis.com/content/disciplines (last visited January 23, 2012).

163 See Mizuki Kawabata et al., Multidisciplinary Cooperation in GIS Education: A Case Study of US Colleges and Universities, 43 J. OF GEOGRAPHY IN HIGHER EDUC. 493, 496-97 (2010).

${ }^{164}$ GIS Mapping Solutions for Industries, ESRI INDUSTRIES, http://www.esri.com/industries.html_(last visited January 23, 2012).

${ }^{165}$ See generally Wagner et al., supra note 28 (arguing that this threat is often realized). 
outputs can conceal these limitations behind a veil of false certitude. ${ }^{166}$ By combining visually compelling graphics with the deceptive precision of numbers, maps heighten these risks, ${ }^{167}$ and spatial analysis tools can easily be misperceived as "truth machines," with their truths all dressed up in pretty colors. ${ }^{168}$ Similarly, increased reliance on quantitative decision-making methodologies threatens to exacerbate digital divides, with highly educated or well-funded elites enjoying preferential access to powerful technologies and poorer or less savvy stakeholders further excluded. ${ }^{169}$ Those fears have reverberated through the spatial analysis literature, with several articles warning, as one put it, that GIS "has effectively raised barriers to empowerment by creating exclusive, sophisticated user-communities beyond the reach of less powerful, resource poor citizens."

These threats of false confidence and digital divides are very real, but technological advances also can promote participation and inclusion. That positive potential derives partly from the increasingly user-friendly interfaces of computing systems and software. Both general operating software and GIS-specific programs are far more intuitive than they were in decades past, computers are cheaper, and the internet makes data and programs much more widely accessible. ${ }^{171}$ The communicative power of maps also increases information availability, for maps can convey large amounts of information in an easily searchable and visually accessible

166 See Fine \& Owen, supra note 28, at 922-34.

167 See Farber, supra note 156, at 1674 (warning that "accessibility and clarity... may cause users to underestimate the amount of uncertainty associated with projections."). See generally DENIS WOOD, THE POWER OF MAPS (1992).

168 See Wagner et al., supra note 28, at 296 (“[M]odels are often misunderstood as 'truth machines' ....”).

${ }^{169}$ See, e.g., Rina Ghose, Use of Information Technology for Community Empowerment: Transforming Geographic Information Systems into Community Information Systems, 5 TRANSACTIONS IN GIS 141, 142 (2001) (warning of "differential access to data and technology").

${ }^{170}$ Id. at 142; see Malczewski, supra note 18, at 8-9 (summarizing critiques).

${ }^{171}$ See Malczewski, supra note 18, at 18 (describing increasingly user-friendly systems); CLARKE, supra note 125 , at 9 (noting the importance of personal computers). 
format. ${ }^{172}$ Spatial analysts also can generate animations, computer-generated views of future land use patterns, and a variety of other visualizations, all capable of making future environmental change more cognitively "available."173 Those advances, in combination with a massive effort by private non-profit groups and by local, state, and particularly federal governmental entities to distribute maps and underlying data, have made extraordinary quantities of information not just accessible, but also potentially comprehensible, to millions of people. ${ }^{174}$ Spatial analysts also have developed multiple ways to actively facilitate participation. With increased computing speed, GIS technicians can sometimes project alternative scenarios within a single meeting, and thus can map several alternative futures as participants watch. ${ }^{175}$ Environmental modelers also can involve lay people in building models. Land conservation modelers, for example, now often build models that allow community members to adjust the importance of different environmental goals - for example, habitat protection, groundwater protection, or aesthetics - and to produce multiple model runs showing how conservation strategies would be affected as preferences change. ${ }^{176}$ Similarly, modelers can ask expert panels to help develop algorithms for selecting parcels for conservation or development, rather than

${ }^{172}$ Sieber, supra note 160 , at 491 (parentheses in original).

${ }^{173}$ See, e.g., David W. Hulse et al., Envisioning Alternatives: Using Citizen Guidance to Map Future Land and Water Use, 14 ECOLOGICAL APPLICATIONS 325, 337 (2004) (showing computer-generated views of development scenarios for Oregon's Willamette River valley). For general discussion of the importance of cognitive availability to decision-making in contexts of uncertainty, see Amos Tversky \& Daniel Kahneman, Availability: A Heuristic for Judging Frequency and Probability, 5 COGNITIVE PsYCHOL. 207 (1973).

${ }_{174}$ See, e.g., Geo.Data.Gov, http://geo.data.gov/geoportal/catalog/main/home.page (last visited December 8, 2011); U.S. Dept. of Ag., Nat'l Res. Conservation Serv., Geospatial Data Gateway, http://datagateway.nrcs.usda.gov/ (last visited December 8, 2011); Ghose, supra note 169, at 143 (describing "public participation geographic information systems" providers).

${ }^{175}$ See, e.g., Kurt Stephenson \& Leonard Shabman, Executing CADRe: Integration of Models with Negotiation Processes, in CONVERGING WATERS, supra note 152, at 23, 33 (describing "[g]aming or what-if exercises"); Trust for Public Land, supra note 20 (explaining TPL's "greenprinting" process); see also Arnab Chakroborty, Enhancing the role of participatory scenario planning processes: Lessons from Reality Check exercises, 43 FUTURES 387, 391 (2011) (describing a "one-day visioning exercise").

${ }^{176}$ See, e.g., Trust for Public Land, supra note 20. 
simply relying on the modelers' intuitions or on historic data. ${ }^{177}$ Lay participants also can run models, perhaps playing roles different from those they occupy in real life, and can thereby better understand the consequences of their actions and the perspectives of competing resource users. ${ }^{178}$ These methods for facilitating participation can be combined. Emerging processes known as "participatory modeling" or "computer-aided dispute resolution" involve stakeholders in iterative processes of building, running, critiquing, and re-running models designed to resolve complex environmental management challenges. ${ }^{179}$

These efforts generally require substantial time investment, but they also can produce significant benefits. ${ }^{180}$ Perhaps most importantly, they can bring multiple perspectives into the model-development process, helping balance policy preferences and unexamined assumptions held by the modelers. ${ }^{181}$ Actively involving non-modelers can be a more effective way of conveying information, allowing participants to be active rather than passive learners. ${ }^{182}$ Involvement also can promote both realism and trust. A participant who has helped develop a

${ }^{177}$ See, e.g., John T. McCloskey et al., Using Bayesian belief networks to identify potential compatibilities and conflicts between development and landscape conservation, 101 LANDSCAPE AND URB. PLANNING 190, 194-95 (2011).

178 See, e.g., Erik Hagen, New Approaches in the Potomac River Basin and Beyond-Pioneering Work in the Development of Shared Vision Planning, in CONVERGING WATERS, supra note 152, at 35, 48 ("The managers gained a new understanding of the system, and a new sympathy for the challenges and positions of the other utilities."); Claudia Pahl-Wostl \& Matt Hare, Process of Social Learning in Integrated Resources Management, 14 J. OF COMMUNITY \& APPLIED PYSCHOL. 193, 198 (2004) (describing benefits of this approach).

${ }^{179}$ Leonard Shabman \& Kurt Stephenson, The Purpose and Goal for CADRe, in CONVERGING WATERS, supra note 152, at 9; see also Hulse et al., supra note 173, at 325 (describing citizen input for land and water use models).

${ }^{180}$ See, e.g., Hagen, supra note 178, at 35, 39 ("[A]n imaginative and groundbreaking water supply solution was conceived and its implementation solved the long-term water supply problem...."); Erica J. Brown Gaddis et al., Effectiveness of a participatory modeling effort to identify and advance community water resource goals in St. Albans, Vermont, 25 EnVTL. MONITORING \& SOFTWARE 1428, 1434-36 (2010) (describing benefits). Despite positive case studies, the empirical literature on the benefits of scenario evaluation and participatory modeling remains thin. Christian Albert, On the influence of scenario-based landscape planning-a comparison of two alternative futures projects, 28 THE PROBS. OF LANDSCAPE ECOLOGY 33, 33 (2010) ("little light has so far been shed on [scenario planning's] effectiveness to change local governance.").

${ }^{181}$ See Fine \& Owen, supra note 28, at 926-30 (explaining the prevalence of judgment in modeling, and the associated importance of public input).

182 See Joan P. Baker et al., Alternative Futures for the Willamette River Basin, Oregon, 14 ECOLOGICAL APPLICATIONS 313, 321 (describing "greater stakeholder understanding, a feeling of ownership in the final product, and increased likelihood that the results will be used."). 
model, or at least has heard it explained and helped run it, is likely to have a more realistic understanding of the limitations and uncertainties of the model, yet also may have more confidence that the modeling outputs do not derive from manipulation or bias. ${ }^{183}$ In an era when environmental debates are routinely undermined by both overconfidence in and distrust of scientific information, building that sort of realism can be crucially important. ${ }^{184}$

Figure 2: Construction of a land use suitability model drawing on Bayesian belief networks. Images courtesy of the Alternative Futures Research Project, Sustainability Solutions Initiative, University of Maine.

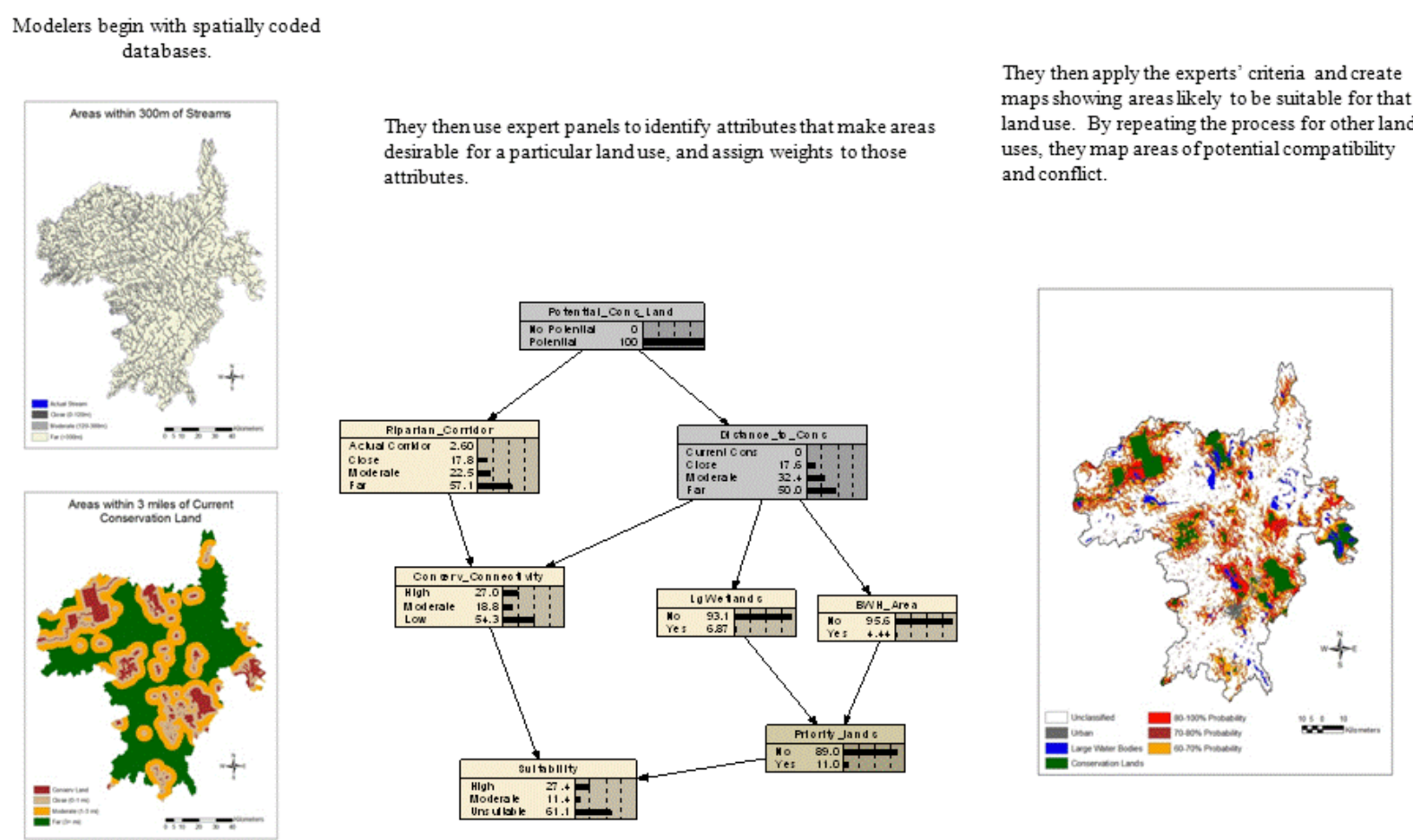

Despite its promise, spatial analysis will never offer perfectly transparent and objective decision-making tools. Uncertainties, concealed subjective choices, and false precision are likely

${ }^{183}$ See Stephenson \& Shabman, supra note 175, at 23, 28 (explaining the value of "model architecture that is transparent").

${ }^{184}$ See Laura K. Schmitt Olabisi et al., Using Scenario Visioning and Participatory System Dynamics Modeling to Investigate the Future: Lessons from Minnesota 2050, 2 SUSTAINABILITY 2686, 2700 (2010) (discussing this potential to "mediate extremes of distrust or blind acceptance"). 
to remain ubiquitous. ${ }^{185}$ Modelers also face difficult tradeoffs between simple models, which are often faster and more transparent, and more complex models, which often, though not always, provide outputs that better correspond to the complexity of the real world. ${ }^{186}$ Even where models perform well, spatial information, like most information, can serve as an instrument of power or exploitation, and increasing the availability of such information does not guarantee that it will be used in just or fair ways. ${ }^{187}$

Nevertheless, if carefully used, these tools hold great promise. If they are to act at all, environmental managers cannot avoid the necessity of trying to understand and, often, predict the behavior of complicated systems. Any set of tools that even incrementally improves those abilities therefore holds potential value, and with spatial analysis, the increments of improvement can be substantial.

\section{Spatial AnAlysis, ENVIRONMENTAL LAW, AND The ChallengES OF GREENACRES}

Despite all the promise of spatial analysis, its emergence has done little to change environmental law. Law does generate many lines on maps; between critical habitat designations, flood insurance mapping, and traditional zoning, to name just a few examples, environmental law and mapping are in some ways closely integrated. ${ }^{188}$ But while environmental lawyers often confront the products of spatial analysis, that does not mean they

185 See Fine \& Owen, supra note 28, at 921-37 (discussing limitations of environmental modeling).

${ }^{186}$ See id. at 924, 926 (discussing advantages and disadvantages of model complexity).

187 See Dorothy L. Hodgson \& Richard A. Schroeder, Dilemmas of counter-mapping community resources in Tanzania, 33 DEVELOPMENT AND CHANGE 79 (2002) (describing well-intentioned exercises with mixed outcomes); Michelle Wilde Anderson, Mapped Out of Local Democracy, 62 STAN. L. REV. 932, 935-949 (2010) (describing political boundaries drawn to exclude relatively poor minority communities).

${ }^{188}$ See U.S. Fish \& Wildlife Serv., FWS Critical Habitat for Threatened \& Endangered Species, http://criticalhabitat.fws.gov/crithab/ (last visited December 11, 2011) (linking to an interactive map); FEMA, Flood Insurance Rate Maps (FIRMs), http://www.fema.gov/hazard/map/firm.shtm (last visited December 11, 2011). 
understand the tools their colleagues in other environmental fields now routinely use. ${ }^{189}$ Instead, legal analyses of spatial data are relatively rare. ${ }^{190}$ And while past changes in environmental science have raised basic questions, often widely discussed, about environmental law, the evolution of spatial analysis technology has generated only a limited academic reaction and minimal legislative or regulatory change. ${ }^{191}$ Among environmental fields, law stands alone in its diffident reaction to the emergent geocoded world.

If environmental law already dealt effectively with all the problems it faced, that diffident reaction would not be problematic. But clearly that is not the case. Environmental scholars routinely identify information management as a central challenge, and that challenge severely constrains environmental law's ability to turn the theoretical appeal of integrated regulation into a practical reality. ${ }^{192}$ For environmental law, then, the emergence of quantitative spatial analysis could represent a crucially important development. This section discusses that potential, and in so doing turns from a general explanation of emerging technology and theory to a somewhat more specific focus on Greenacres and the environmental challenges of urbanization. The discussion is by no means exhaustive. Nevertheless, even a few examples from one sub-field of environmental law should illustrate the potential breadth of spatial analysis's implications, and the ways it can facilitate more integrative regulatory approaches.

\section{A. What We Understand}

${ }^{189}$ See Salkin \& Nolon, supra note 26, at 526 ("While planning schools offer hands-on courses in the use of these new technologies, they are not typically part of the curriculum in law school.").

${ }^{190}$ See supra note 26 and accompanying text.

${ }^{191}$ See Mary Jane Angelo, Harnessing the Power of Science in Environmental Law: Why We Should, Why We Don't, and How We Can, 86 TEX. L. REV. 1527, 1527 (2008) ("Environmental law was born out of the new scientific understandings of ecology...."); A. Dan Tarlock, The Nonequilibrium Paradigm in Ecology and the Partial Unraveling of Environmental Law, 27 LOYOLA L.A. L. REV. 1121 (1993); Donald T. Hornstein, Reclaiming Environmental Law: A Normative Critique of Comparative Risk Analysis, 92 CoLUM. L. REV. 562 (1992).

${ }^{192}$ See, e.g, Holly Doremus, Data Gaps in Natural Resource Management: Sniffing for Leaks along the Information Pipeline, 83 IND. L.J. 407, 408 (2008); Wagner, supra note 16. 
Perhaps the most important way spatial analysis can change environmental law is by improving our understanding of environmental problems. Almost any regulatory response to an environmental problem requires a demonstration that the problem exists, some explanation of its causes, and a reasonably robust understanding of how individual activities create problems manifested at broader temporal and spatial scales and across jurisdictional boundaries. ${ }^{193}$ If the regulatory response is to be effective, it also requires some understanding of the negative tradeoffs and positive synergies likely to arise from regulatory intervention, including tradeoffs and synergies that span the compartmental boundaries of individual regulatory programs. ${ }^{194}$ Because of the complex, multi-scalar, and intertwined nature of environmental problems and regulatory responses, achieving that understanding can be difficult, and those difficulties can limit the problems we respond to, or even recognize. ${ }^{195}$ As the following examples illustrate, however, advances in spatial analysis can expand that realm of understanding.

\section{Diagnosing Environmental Problems}

Sometimes an environmental problem and its source are obvious to anyone who cares to look. Pollution belching from a factory or untreated sewage discharging from a pipe can demand attention, and the impacts, at least in the immediate vicinity of the discharge, can be difficult to miss. But many present-day environmental challenges - including many challenges associated with land use change_-involve multiple stressors, some acting through geographically or temporally attenuated chains of causation. ${ }^{196}$ Understanding those causal relationships can be

\footnotetext{
${ }^{193}$ See supra notes 74-77 and accompanying text (discussing the tendency for large environmental problems to arise from an accumulation of smaller impacts).

${ }^{194}$ See supra notes 43-57 and accompanying text.

195 See generally Boyd, supra note 26, at 847 (developing this argument).

196 See Ruhl \& Salzman, supra note 74, at 88-92; Carol Rose, The Story of Lucas: Environmental Land Use Regulation Between Developers and the Deep Blue Sea, in ENVIRONMENTAL LAW STORIES 239 (Richard J. Lazarus $\&$ Oliver A. Houck eds. 2005) (exploring how incremental change complicates land use regulation).
} 
nearly impossible without a large, spatially coded data set and a computational model. ${ }^{197}$

Consequently, spatial analysis now plays a central role in monitoring environmental changes and in diagnosing environmental problems, particularly when those problems manifest themselves at broad spatial or temporal scales. ${ }^{198}$ The applications are far too numerous to list, but of many possible examples, the relationship between urbanization and water quality illustrates particularly well how spatial analysis can transform our capacity to understand, and respond to, environmental problems.

For decades, environmental scientists have understood, at least at a general level, that urbanization degrades water quality. ${ }^{199}$ As development progresses, both dry spells and floods become more extreme, aquatic and riparian habitats are degraded or disappear, water temperatures become more variable, and pollutant loads increase. ${ }^{200}$ At even sparse suburban densities, the result is usually an impaired waterway, particularly if the watershed is small. ${ }^{201}$ Environmental scientists have understood these general dynamics for years. But building a regulatory regime has been difficult, largely because of the informational challenges associated with translating a general understanding of watershed degradation into site-specific regulatory controls, and because of jurisdictional divides between federal environmental regulation and local land use control. ${ }^{202}$ The primary focus of water quality regulation instead has largely been the sort of large, discrete sources amenable to regulatory coverage under a temporally and

197 See Oreskes, supra note 155, at 70-71.

198 See, e.g., id. at 71 (describing several applications); COMM. ON MODELS IN THE REGULATORY DECISION PROCESS, supra note 126, at ix (stating that modeling is necessitated by "[t]he spatial and temporal scales at which environmental controls and environmental quality are linked").

199 See LUNA LEOPOLD, U.S. DEPT. OF THE INTERIOR, HYDROLOGY FOR URBAN PLANNING-A GUIDEBOOK ON THE HYDROLOGIC EFFECTS OF URBAN LAND USE 15-17 (1968).

${ }^{200}$ See Christopher J. Walsh et al., The Urban Stream Syndrome: Current Knowledge and the Search for a Cure, 24 J. N. AM. BENTHOLOGICAL SOC'Y 706 (2005).

${ }^{201}$ Id.; see COMM. ON REDUCING STORMWATER Discharge CONTRIBUTIONS TO WATER POLLUTION, NAT’L RESEARCH COUNCIL, URban STORMWATER MANAGEMENT IN THE UNITED STATES 20-26 (2009); CTR. FOR WATERSHED PROT., IMPACTS OF IMPERVIOUS COVER ON AQUATIC SYSTEMS 2 (2003).

${ }^{202}$ See Owen, supra note 2, at 445-50 (explaining these challenges). 
geographically focused, media-specific regulatory regime. ${ }^{203}$ Consequently, many metropolitan areas developed with minimal regard to water quality protection, and impaired waterways are now pervasive features of American suburban and urban landscapes. ${ }^{204}$

In recent years, spatial analysis has helped researchers build a more robust conceptual foundation for addressing these problems. By comparing spatially coded water quality data with land use and land cover data, environmental scientists have refined their understanding of the dynamics of urban water quality impairment. A series of studies has identified a close relationship between impervious cover—primarily roads, roofs, and pavement—and water quality impairment, and has identified rough impervious cover thresholds above which water quality impairment nearly invariably occurs. ${ }^{205}$ That finding has transformative implications for water quality regulation. It connects individual increments of land development—an activity already subject to regulation, but through local land use regulations and building codes rather than federal water quality law-with a broader-scale environmental problem that previously seemed intractable. ${ }^{206}$ Some recent research initiatives have gone a step further, and can bring spatial data on water supply withdrawals into the analysis. ${ }^{207}$ The result of this work is an improved understanding of the relationships between urban development and aquatic ecosystems.

${ }^{203}$ See id. at 446.

${ }^{204}$ See id. at 443-44 (describing the pervasiveness of the problem).

${ }^{205}$ See CTR. FOR WATERSHED PROT., supra note 201, at 1-2; NRC, supra note 201, at 226-30. Some recent studies have found that degradation begins at even lower levels of development. See, e.g., Thomas F. Cuffney et al., Responses of Benthic Macroinvertebrates to Environmental Changes Associated with Urbanization in Nine Metropolitan Areas, 20 ECOLOGICAL APPLICATIONS 1384, 1398 (2010).

${ }^{206}$ See Owen, supra note 2, at 462-63 (describing how a focus on impervious cover can facilitate local responses).

${ }^{207}$ See, e.g., DAVID S. ARMSTRONG ET AL., PRELIMINARY ASSESSMENT OF FACTORS INFLUENCING RIVERINE FiSH COMMUNITIES IN MASSACHUSETTS (2010), http://pubs.usgs.gov/of/2010/1139/pdf/ofr2010-1139.pdf. 
In addition to helping researchers understand the dynamics of present problems, spatial analysis also can help identify areas where future water quality problems are likely to arise. Some studies have used "build-out" analyses, which assume future development to the full extent allowed by current zoning, to predict the extent and geographic location of future water quality problems if a community's growth aspirations are fulfilled. ${ }^{208}$ Those build-out analyses also can be adapted to predict impairment under alternative zoning regimes, providing a community with some sense of the implications of alternative growth strategies. ${ }^{209}$ They also can expand the analytical focus from the community to the regional scale, examining, for example, the aggregate water quality impacts created if individual communities use large-lot zoning or other growthspreading regulatory regimes. ${ }^{210}$ By integrating economic growth models into future land use projections, modelers also now can go beyond these build-out analyses and create more nuanced projections of the extent and location of future development. ${ }^{211}$ That could help water quality regulators and land use planners not just understand, but also improve, the relationship between developments like Greenacres and regional water quality trends. ${ }^{212}$

${ }^{208}$ See, e.g., Conway \& Lathrop, supra note 20 (assessing buildout scenarios for coastal New Jersey).

${ }^{209}$ See, e.g., id. at 9.

${ }^{210}$ See U.S. EPA, Protecting Resources With Higher Density DeVElopMent 11-25 (2006).

${ }^{211}$ Several collaborators and I are currently developing a water quality model that uses this approach, which is particularly appropriate where zoning classifications are either aspirational, negotiable, or both, and a buildout scenario therefore is implausible. However, buildout analyses have the advantage of using relatively simple, transparent rules. See Robert Gilmore Pontius Jr. \& Neeti Neeti, Uncertainty in the difference between maps of future land use scenarios, 5 SUSTAINABILITY SCI. 39, 46, 48 (2010) (stressing these advantages).

${ }^{212}$ See, e.g., Baker et al., supra note 182, at 316 (2004) (describing a modeling process that contrasted river and stream conditions under alternative future regulatory regimes). 
By providing visually accessible outputs, spatial analysis also can help modelers and scientists explain water quality problems to lay audiences, and thus can expand the realm of understanding beyond technically sophisticated regulatory agency staff. A map showing projected future impervious cover under alternative regulatory regimes can clarify the implications of local land use planning decisions in ways that prose-based descriptions cannot match. ${ }^{213}$ Similarly, even a relatively simple concept, like the Figure 3: Large lot zoning and impervious area. From U.S. Environmental Protection Agency, supra note 210, at 17.

relationship between large-lot

zoning and aggregate impervious

cover levels, is far easier to

explain with a conceptual map

than with a series of sentences. ${ }^{214}$

Sophisticated models can add

even more explanatory power.

One intriguing example is the

UVa Bay Game, a model that

\begin{tabular}{|c|c|c|}
\hline Scenario A & Scenario B & Scenario C \\
\hline & & \\
\hline $\begin{array}{l}10,000 \text { houses built on } \\
10,000 \text { acres produce: }\end{array}$ & $\begin{array}{l}10,000 \text { houses built on } \\
2,500 \text { acres produce: }\end{array}$ & $\begin{array}{l}10,000 \text { houses built on } \\
1,250 \text { acres produce: }\end{array}$ \\
\hline $\begin{array}{l}10,000 \text { acres } \times 1 \text { house } \\
\times 18,700 \mathrm{ft}^{3} / \mathrm{yr} \text { of } \\
\text { runoff }=\end{array}$ & $\begin{array}{l}2,500 \text { acres } \times 4 \text { houses } \\
\times 6,200 \mathrm{ft}^{3} / \mathrm{yr} \text { of } \\
\text { runoff }=\end{array}$ & $\begin{array}{l}1,250 \text { acres } \times 8 \text { houses } \\
\times 44,950 \mathrm{ft}^{3} / \mathrm{yr} \text { of } \\
\text { runoff }=\end{array}$ \\
\hline $\begin{array}{l}187 \text { million } \mathrm{ft}^{3} / \mathrm{yr} \text { of } \\
\text { stormwater runoff }\end{array}$ & $\begin{array}{l}62 \mathrm{million} \mathrm{ft}^{3} / \mathrm{yr} \\
\text { of stormwater runoff }\end{array}$ & $\begin{array}{l}49.5 \text { million } \mathrm{ft}^{3} / \mathrm{yr} \text { of } \\
\text { stormwater runoff }\end{array}$ \\
\hline $\begin{array}{l}\text { Site: } 20 \% \text { impervious } \\
\text { cover }\end{array}$ & $\begin{array}{l}\text { Site: } 38 \% \text { impervious } \\
\text { cover }\end{array}$ & $\begin{array}{l}\text { Site: } 65 \% \text { impervious } \\
\text { cover }\end{array}$ \\
\hline $\begin{array}{l}\text { Watershed: } 20 \% \\
\text { impervious cover }\end{array}$ & $\begin{array}{l}\text { Watershed: } 9.5 \% \\
\text { impervious cover }\end{array}$ & $\begin{array}{l}\text { Watershed: } 8.1 \% \\
\text { impervious cover }\end{array}$ \\
\hline
\end{tabular}

allows users to act as farmers, municipalities, environmental regulators, and other players in the complex dynamics of protecting Chesapeake Bay. ${ }^{215}$ Researchers report that the game already has proven a valuable educational tool, helping both students and actual stakeholders understand the interconnections and complexities involved in Chesapeake Bay management. ${ }^{216}$

${ }^{213}$ See, e.g., Conway \& Lathrop, supra note 20, at 9.

${ }^{214}$ See, e.g., U.S. ENVTL. PROT. AGENCY, supra note 210, at 17.

${ }^{215}$ See the uva bay game, at http://www.virginia.edu/baygame/ (last visited November 21, 2011).

${ }^{216}$ Gerard P. Learmonth Sr., A practical approach to the complex problem of environmental sustainability: the UVa Bay Game, 16 THE InNOVATION JouRnal: JouRnal of PUbliC INNOVATION __, 4 (2011), http://www.innovation.cc/scholarly-style/learmonth_sustain_inviroment_v16i1a4.pdf (describing positive results). 
In sum, these advances are helping watershed scientists and regulators overcome the temporal, spatial, and jurisdictional fragmentation that often hamstrings efforts to address the environmental consequences of urbanization. And watershed scientists are by no means the only ones using spatial analysis to understand the environmental impacts of urbanization. Ecologists for years have used spatial models to track the impacts of regional development upon habitat, and to identify areas particularly under threat, and their analytical tools continue to evolve. ${ }^{217}$ While connections between air quality regulation and land use planning have traditionally been attenuated, ${ }^{218}$ numerous studies now model the air quality implications of alternative development patterns, and quantifying the aggregate air quality impacts of many developments like Greenacres is increasingly feasible. ${ }^{219}$ Consequently, some new regulatory initiatives now integrate development permits and air quality control. ${ }^{220}$ Similar analytical tools could help link developments like Greenacres with specific increents of greenhouse gas emissions. ${ }^{21}$ All of these efforts are increasing our capacity to understand the relationships between developments like Greenacres and the goals reflected in a wide variety of environmental laws.

These advances have their limits, and water quality modeling exemplifies the continuing challenges as much as the positive potential. No water quality model can precisely and

${ }^{217}$ See, e.g., Jeffrey A. Hepinstall et al., Predicting land cover change and avian community responses in rapidly urbanizing environments, 32 LANDSCAPE ECOLOGY 1257 (2008); David M. Theobald, Targeting Conservation Action through Assessment of Protection and Exurban Threats, 17 CONSERVATION BIOLOGY 1624 (2003).

${ }^{218}$ See Patrick Del Duca \& Daniel Mansueto, Indirect Source Controls: An Intersection of Air Quality Management and Land Use Regulation, 24 LOY. L.A. L. REV. 1131, 1149-55 (1991) (describing failed integration efforts).

${ }^{219}$ See DRIVING AND THE BUILT ENVIRONMENT, supra note 3, at 3 (summarizing studies, and concluding that "[d]eveloping more compactly... is likely to reduce VMT").

${ }^{220}$ See Nat'l Assoc. of Home Builders v. San Joaquin Valley Unified Air Pollution Control Dist., 627 F.3d 730, 731-32 (9th Cir. 2010), cert denied, 132 S.Ct. 369 (2011) (describing a rule imposing air quality impact mitigation fees on development projects).

${ }^{221}$ See DRIVING AND THE BUILT ENVIRONMENT, supra note 3, at 2 (noting that greenhouse gas emissions associated with land use change are largely due to fossil fuel consumption, which also generates conventional air pollutants). 
accurately quantify the impacts of each individual development, or even the aggregate consequences of a growth program or regulatory regime. Instead, data gaps and errors are ubiquitous, and some relationships remain poorly understood. ${ }^{222}$ Even where understanding is robust, models still must reduce the complexity of real-world ecological interactions to a relatively simple set of algorithms and equations. ${ }^{223}$ But if modeling produces a general understanding of the dynamics of environmental impairment and provides some basis for comparing alternative regulatory approaches, and if candid disclosures accompany the model results, even an imperfect effort can provide analytical traction for problems that regulators previously grasped only at the most conceptual of levels. ${ }^{224}$

\section{Recognizing Tradeoffs and Synergies}

Helping researchers understand and explain a particular environmental problem, like the relationship between urbanization and water quality, is a significant achievement. But Greenacres' water resource impacts will likely overlap with impacts on a variety of other environmental media and non-environmental outcomes. Similarly, some regulatory responses to Greenacres' water impacts may create counterproductive results for other environmental goals, or for economic outcomes, while others may produce synergistic benefits. ${ }^{225}$ Understanding those tradeoffs and opportunities also has been a central challenge, often unmet, for

\footnotetext{
${ }^{222}$ See Christer Nilsson et al., Ecological Forecasting and the Urbanization of Stream Ecosystems: Challenges for Economists, Hydrologists, Geomorphologists, and Ecologists, 6 ECOSYSTEMS 659, 660 (2003) (“our ecological forecasts were crude, largely qualitative in nature, and essentially based on expert knowledge... and correlative evidence.")

${ }^{223}$ See generally Fine \& Owen, supra note 28, at 922-30. of policies).

${ }^{224}$ See generally ALBERTI, supra note 21, at 225 (noting that planners must evaluate the future implications ${ }^{225}$ See supra notes 52-57 and accompanying text.
} 
environmental law. ${ }^{226}$ But in several ways, spatial analysis already is improving responses to multifaceted environmental problems, with the potential for substantial additional gains.

One of the best illustrations of this potential, and one of the most frequent applications of spatial analysis, involves mapping multiple environmental constraints when siting development projects. $^{227}$ Most development projects are subject to multiple regulatory constraints that can be depicted spatially. For example, wetlands, floodplains, zoning controls, conservation lands, and protected habitat areas all can be mapped, and all provide important signals about where a project might face a difficult regulatory process. ${ }^{228}$ Similarly, many landscape features desired by developers, like favorable soils and slopes, low taxes, quality school districts, proximity to complementary businesses, and access to roads and other pre-existing infrastructure, also can be mapped. ${ }^{229}$ If the map layers are publicly available — and in many communities, they are - GIS technology allows developers to find areas that maximize positive features and minimize negative ones, and also allows local officials to steer development projects toward particularly promising sites. $^{230}$

${ }^{226}$ See supra Part I.A.

${ }^{227}$ See generally Malczewski, supra note 18, at 4 (describing applications).

${ }^{228}$ See, e.g., Office of Geographic Information (MassGIS), http://www.mass.gov/mgis/ (last visited August 25,2011 ) (linking to a mapping tool); U.S. Fish \& Wildlife Serv., supra note 188.

${ }^{229}$ See, e.g., McCloskey et al., supra note 177, at 192-94.

${ }^{230}$ See, e.g., MassGIS, supra note 228. Recently, ocean spatial planners have begun using similar techniques. See, e.g., MASSACHUSETTS OCEAN MANAGEMENT PLAN (2009), at http://www.env.state.ma.us/eea/mop/final-v1/v1-complete.pdf. 
The same approach can target conservation efforts. A land trust might overlay data layers showing wetland resources, aquifer recharge zones, rare plant and wildlife habitats, and potential habitat corridors to determine where to scales, conservation organizations often use a Figure 4: Land use suitability map, Lower Penobscot River watershed, Maine. Image courtesy of Rob process called "gap analysis," which involves using GIS to identify regionally underprotected habitat types. ${ }^{232}$ They also can use economic development models to identify parcels where development potential is high, and therefore the threat to resources is larger, or where development potential is lower, and purchase prices and conflict with community economic development goals are likely to be low. ${ }^{233}$ Likewise, economic models can explore whether purchase- or zoning-based strategies would more effectively accomplish


conservation goals and can test the potential economic side-effects of environmental protection strategies. $^{234}$

${ }^{231}$ See, e.g., TRust for Public LAND, The PenobSCot VALley Community GreENPRINT 20 (2009).

${ }^{232}$ See Theobald et al., supra note 4, at 1625 (describing gap analysis).

${ }^{233}$ See, e.g., Kathleen A. Lohse et al., Forecasting Relative Impacts of Land Use on Anadromous Fish Habitat to Guide Conservation Planning, 18 ECOLOGICAL APPLICATIONS 467, 479 (2008) (describing this tradeoff).

${ }^{234}$ See, e.g., D.T. Robinson \& D.G. Brown, Evaluating the effects of land-use development policies on exurban forest cover: An integrated agent-based GIS approach, 23 INT'L J. OF GEOGRAPHIC INFORMATION SCI. 1211, 1221-30 (2009); John M. Quigley \& Aaron M. Swoboda, The Urban Impacts of the Endangered Species Act: A General Equilibrium Analysis, 61 J. URB. ECON. 299 (2007). 
Like other applications of spatial analysis, these uses have significant limitations.

Turning land use and land cover databases, which usually contain gaps and inaccuracies, into suitability maps inevitably involves some distortion and oversimplification ${ }^{235}$ Features like a community's receptivity to development, the efficiency of a town's regulatory approval processes, and the willingness of state or local governments to grant variances or leave laws unenforced all have important implications for development patterns but are not easily mapped. Consequently, spatial analysis is not a perfect tool for identifying all the implications of development proposals or regulatory initiatives. But it can facilitate simultaneous consideration of a variety of different environmental and non-environmental opportunities and constraints, and exploration of some of the implications of planned activities. In these capacities, it now sees widespread use, with new innovations continuing to emerge. ${ }^{236}$

\section{Modeling Complicated Systems}

The emergence of tools for conceptualizing individual environmental problems or siting individual projects is quite important in its own right, but these capabilities also form building blocks toward a larger goal. The complex relationships among multiple environmental challenges, human activities, and regulatory policies create a need for ways to understand larger human-ecological systems as well as one or a few components of those systems. ${ }^{237}$ Again, innovations in spatial analysis hold promise.

\footnotetext{
${ }^{235}$ See generally WoOD, supra note 167, at __ (noting that maps often draw sharp lines where natural conditions form more of a continuum).

${ }^{236}$ See Malczewski, supra note 18, at 4 ("GIS-based land-use suitability analysis has been used in a wide variety of situations...”). The Obama Administration has called for a major increase in spatial mapping in ocean and coastal areas. See THE White House Council on EnVtL. QuAlity, supra note 101

${ }^{237}$ See Marina Alberti \& Paul Waddell, An integrated urban development and ecological simulation model, 1 INTEGRATED ASSESSMENT 215, 215 (2000).
} 
In recent years, spatial analysts have begun creating comprehensive urban simulation models. ${ }^{238}$ Rather than modeling a single component of the urban system, these models would integrate multiple systems, including transportation, land uses, employment and economic outcomes, municipal finances, and a range of environmental outcomes, into systemic models. ${ }^{239}$ These models would have the capacity to simulate possible futures, testing, for example, the potential effects of different regulatory regimes upon a range of environmental and nonenvironmental outcomes. ${ }^{240}$ More conceptually, the models should be able Figure 5: Conceptual Diagram of an urban growth model. Image courtesy of Charles Colgan, University of Southern Maine, and adapted from urbanism.org.

to explore and predict ways in which environmental outcomes both derive from and drive other urban dynamics. ${ }^{241}$ Ambitious though it may sound, the modelers' goal is a quantitative, spatially explicit representation of the coupled human and natural ecology of

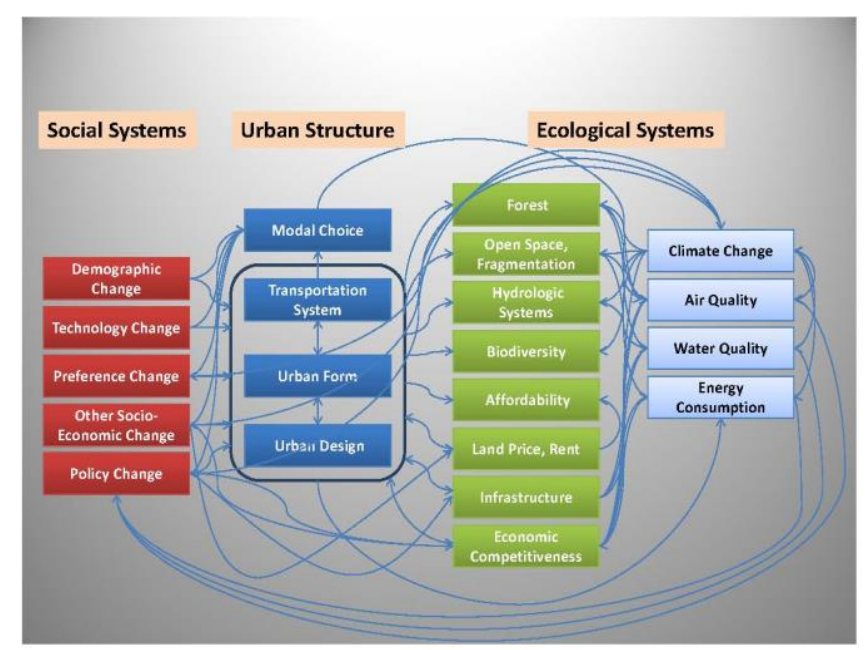
urban systems. $^{242}$

Modelers are pursuing this goal in a variety of ways. Some use "cellular automata" models, which divide the study area into grid cells, each assigned a particular set of values, and

${ }^{238}$ See, e.g., Paul Waddell, UrbanSim: Modeling Urban Development for Land Use, Transportation, and Environmental Planning, 68 J. AM. PLANNING ASSOC. 297 (2002); John D. Landis, Imagining Land Use Futures: Applying the California Urban Futures Model, 61 J. AM. Plan. AsS'N. 438 (1995).

${ }^{239}$ See, e.g. UrbanSim, at urbanism.org (last visited January 23, 2012).

${ }^{240}$ See, e.g., Baker et al., supra note 182 (describing a multifaceted modeling effort for Oregon's Willamette Basin).

${ }^{241}$ See S.T.A. Pickett et al., Urban Ecological Systems: Scientific foundations and a decade of progress, 92 J. EnVTL. MGMT. 331, 351-52 (2011) (discussing the challenges of modeling integrated social and ecological processes).

${ }^{242}$ See generally Alberti, supra note 21. 
then project landscape change through an iterative process of updating each cell's values based on the values of neighboring cells. ${ }^{243}$ "Agent-based models" simulate land use change by modeling the behavior of multiple actors, each trying to achieve some set of economic, social, or environmental goals, and each reacting to other actors and to the changing landscape. ${ }^{244}$ "Bayesian belief network" models utilize expert opinions to develop a set of model rules and preferences and then combine those preferences with land use and land cover data to simulate future changes. ${ }^{245}$ Multiple other techniques exist, and many of these approaches can be combined. ${ }^{246}$ Indeed, some of the most complex modeling systems are really aggregations of multiple models. ${ }^{247}$

Despite this explosion of methodologies, building an urban model that provides reliable predictions remains an aspirational goal. The input data needs of highly complex urban models are extraordinary. ${ }^{248}$ While some spatial data sets are now widely available, mismatches between the modelers' needs and available data sets are almost certain to occur. ${ }^{249}$ Other modeling techniques, like Bayesian belief network modeling, create lesser (though still significant) data demands, but their reliance on expert convention heightens the risk that the

${ }^{243}$ See Diana Mitsova et al., A cellular automata model of land cover change to integrate urban growth with open space conservation, 99 LANDSCAPE AND URBAN PLANNING 141, 143 (2011).

${ }^{244}$ See Pickett et al., supra note 241, at 352; Elena G. Irwin \& Jacqueline Geoghegan, Theory, data, methods: developing spatially explicit economic models of land use change, 85 AGRICULTURE, ECOSYSTEMS, AND ENV'T 7 (2003) (praising agent-based modeling).

${ }^{245}$ See, e.g., McCloskey et al., supra note 177.

${ }^{246}$ See Peter Gomben \& Robert Lilieholm, Impact of Demographic Trends on Future Development Patterns and the Loss of Open Space in the California Mojave Desert, _ ENVTL. MGMT. __ (forthcoming 2012) (explaining multiple techniques);

${ }^{247}$ See, e.g., Waddell, supra note 238, at 303 (describing UrbanSim as "a software architecture for implementing models and a family of models implemented and interacting within this environment"); Hulse et al., supra note 173, at 331 (diagramming a set of interlocking models).

${ }^{248}$ See Hulse et al., supra note 173, at 327 (describing a two-year data gathering effort).

${ }^{249}$ See Pontius Jr. \& Neeti, supra note 211, at 41, $46-48$ (2010) (describing sources of uncertainty). 
model will incorporate rather than challenge flaws in conventional wisdom. ${ }^{250}$ Additionally, any model's internal logic is effectively a set of simplified assumptions about the behavior of human and environmental systems, and there are many aspects of that behavior that we poorly understand, or that we simply cannot predict. ${ }^{251}$ As the complexity of the model grows, the combined effect of uncertainties and judgments can grow as well, leading to poor simulations and also inhibiting error detection. ${ }^{252}$

For all of these reasons, the day is a long way off when urban modelers can take a municipality's proposed general plan, plug it into a model, and quickly produce reliable predictions about air quality, water quality, ESA compliance, economic growth, governance costs, transportation efficiency, and the social equity implications of both regulation and development. ${ }^{253}$ Even further away, if it ever comes, is the day when modelers can provide those predictions for a single development project. $^{254}$ The current generation of highly integrative urban models is better viewed as a preliminary set of exploratory tools, usually best applied at broad geographic scales, rather than as comprehensively accurate and detailed representations of urban systems. ${ }^{255}$ Nevertheless, even in their present state, urban growth models can help policymakers understand the likely environmental consequences of development trends, and to

${ }^{250}$ See McCloskey et al., supra note 177, at 191 ("BBN models are particularly useful when empirical data are limited and decisions are based largely on expert knowledge...."). BBN modeling relies on people's opinions, which may be informed and accurate, but people are often ignorant of biases driving their own decision-making. See generally DANIEL KAHNEMAN, THINKING, FAST AND SLOW (2011).

${ }^{251}$ See Pontius, Jr. \& Neeti, supra note 211, at 41 (noting the potential for modeled algorithms to poorly reflect actual processes); Pickett et al., supra note 241, at 352 ("identifying causal effects of land use change is extremely challenging").

${ }^{252}$ See COMM. ON Models IN THE Regulatory DeCision Process, supra note 126, at 10 (advocating "model parsimony").

${ }^{253}$ In comments on an earlier draft, Kelley Hart of the Trust for Public Land pointed out that the lack of specificity in many general plans also would limit such analyses.

${ }^{254}$ See, e.g., R.D. Swetnam et al., Mapping socio-economic scenarios of land cover change: A GIS method to enable ecosystem service modeling, 92 J. ENVTL. MGMT. 563, 573 (2011) (noting that modeled scenarios can have greater value at larger geographic scales).

${ }^{255}$ See id. at 564 ("[E]ach scenario should be thought of as a description of a possible future, albeit one which is plausible...."). 
assess the sensitivity of those trends to different economic scenarios and regulatory

interventions. ${ }^{256}$ Because of these capabilities, complex urban models already are important to environmental planners, and the push to develop more sophisticated tools shows no sign of abating. ${ }^{257}$ The time may yet arrive when many environmental and non-environmental regulatory processes can be linked through computer-based simulations, allowing policymakers to think about multiple environmental goals, at multiple scales, and across jurisdictional boundaries all at once.

\section{B. How We Regulate: Changing Legal Instrument Selection}

The evolution of spatial analysis has important implications not just for our conceptualization of the dynamics of environmental change, but also for the legal tools we use to address these dynamics. Without exhausting the field, this section discusses two ways in which spatial analysis can support instruments that attempt to integrate regulation across spatial and temporal scales and media-specific boundaries, and thus can shift environmental law's core debates about regulatory instrument choice.

\section{Muddling toward Synoptic Regulation}

One of environmental law's most venerable debates concerns regulatory approaches that demand information-intensive studies or plans. Environmental assessment laws like NEPA, which requires far-ranging environmental impact statements in advance of governmental actions, exemplify one version of this approach. ${ }^{258}$ Comprehensive planning statutes provide another common example. ${ }^{259}$ In theory, these laws should facilitate the sort of broad, integrative

${ }^{256}$ See, e.g., Baker et al., supra note 182 (considering the implications of the Willamette Basin's development trends).

${ }^{257}$ See Gomben \& Lilieholm, supra note 246, at __ (noting many existing uses); UrbanSim, at UrbanSim.org (listing dozens of countries where versions of UrbanSim have been used).

25842 U.S.C. $\$ 4332$ (C) (2006).

${ }^{259}$ See supra note 82 (citing multiple planning requirements). 
thinking that almost everyone agrees is desirable. ${ }^{260}$ The practical utility of those laws has been hotly debated for decades, however, with one representative critique asserting that "NEPA ambitiously, and naively, demands the impossible: comprehensive, synoptic rationality, in the form of an exhaustive, one-shot set of ex ante predictions of expected environmental impacts. In the ordinary course of events, that task proves insuperable."261 Planning's skeptics often say much the same thing, and argue that alternative regulatory approaches should receive more emphasis. $^{262}$

These debates have important practical implications. Both environmental assessment laws and planning statutes occupy influential roles in federal and state environmental law. ${ }^{263}$ But they are not ubiquitous. Most states lack laws like NEPA, and many states and localities have a fairly uneven commitment to planning. ${ }^{264}$ Consequently, many sources of environmental impact, including the kind of urban development exemplified by Greenacres, are only partially and unevenly covered. ${ }^{265}$ Even where such laws do exist, their continued application is controversial. NEPA continues to generate legislative and administrative complaints, with federal agencies

${ }^{260}$ See Calvert Cliffs' Coordinating Comm. v. U.S. AEC, 449 F.2d 1109, 1114 (D.C. Cir. 1971) (arguing that only through such broad analyses is it "likely that the most intelligent, optimally beneficial decision will ultimately be made").

${ }^{261}$ See Bradley C. Karkkainen, Toward a Smarter NEPA: Monitoring and Managing the Government's Environmental Performance, 102 CoLUM. L. REV. 903, 907 (2002).

${ }^{262}$ See, e.g., Oliver A. Houck, Of Bats, Birds and B-A-T: The Convergent Evolution of Environmental Law, 63 Miss. L.J. 403, 410-28 (1994) (critiquing environmental planning).

${ }^{263}$ See FARBER ET AL., supra note 55, at 522 ("NEPA has remained an important pillar of environmental law."); Dave Owen, Probabilities, Planning Failures, and Environmental Law, 84 TUL. L. REV. 265, 266-67 (2009) (describing environmental law's extensive planning requirements).

${ }^{264}$ See DANIEL MANDELKER, NEPA LAW AND LITIG. § 1:7 (2011) (“state environmental policy acts... have been enacted in 15 states, Puerto Rico and the District of Columbia"). Some states without full-blown environmental policy acts still require some environmental review of development projects. See, e.g., Maine Site Location of Development Law, Me. Rev. Stat. Ann. tit. 30-A, §§ 481-490 (West 2001).

${ }^{265}$ NEPA still applies to some development projects, but only to the extent they trigger discretionary federal review. See 42 U.S.C. § 4332(C) (2006) (establishing requirements for “major Federal actions"). 
often seeking opportunities to "streamline" its processes. ${ }^{266}$ Initiatives to limit the applicability of state environmental assessment requirements are also quite common. ${ }^{267}$ Federal, state, and local governments therefore often debate how much, if at all, to pursue comprehensive planning and environmental review requirements. ${ }^{268}$

Advances in spatial analysis have important implications for these debates. While spatial analysis cannot make the challenges of synoptic analysis disappear, it can expand the realm of the possible, making spatially and temporally broad analyses viable where they previously were unrealistically ambitious. The ability of models to simulate the combined effect of many different emission sources on regional air pollution, or of a variety of land use changes upon water quality, both exemplify that capacity. ${ }^{269}$ Similarly, spatial analysis can facilitate the multimedia inquiries that environmental laws like NEPA are supposed to promote. Environmental impact assessment laws provide a rare obligation to address, in a single process leading to a unified document, the impacts of a project on a variety of environmental media, and to consider alternatives to that project. $^{270}$ That obligation would mean little if environmental scientists lacked the tools to produce the required predictions, and instead were providing encyclopedic compilations of semi-informed guesswork. ${ }^{271}$ But as modeling capabilities increase, retaining a procedural obligation for cross-media, multi-scalar analysis will likely become increasingly important.

${ }^{266}$ See Bradley C. Karkkainen, Whither NEPA?, 12 N.Y.U. ENVTL. L. J. 333, 336-38 (2004) (describing initiatives, in response to "[1] ong-simmering dissatisfaction among agency officials and resource extraction industries," to limit NEPA).

${ }^{267}$ See, e.g., Timm Herdt, Lawmakers approve measures to speed up large developments, VENTURA COUNTY STAR, September 10, 2011.

268 See, e.g., WhITE HOUSE COUNCIL ON ENVTL. QUALITY, supra note 101 (proposing ambitious new planning initiatives for marine resource management).

${ }^{269}$ See supra notes 205-217 and accompanying text.

${ }^{270}$ See supra notes 48-73 and accompanying text.

${ }^{271}$ See Paul J. Culhane, The Precision and Accuracy of U.S. Environmental Impact Statements, 8 ENVTL. MONITORING \& ASSESSMENT 217, 235-36 (1987) (questioning the value of predictions in NEPA documents). 
Those advances do not imply that we should abandon the hedge strategies we have adopted to compensate for pervasive informational shortfalls. Technology-based standards, adaptive management programs, and all the other ways we now address the informational challenges of environmental regulation all will continue to play important roles. ${ }^{272}$ But increases in our analytical capacity clearly do mean that the debate over these competing approaches needs to evolve. Comprehensive planning and analysis have produced uneven results, but as we choose among regulatory instruments, past limitations should not prevent us from asking whether technological advances are closing the gaps between our synoptic ambitions and our practical realities. ${ }^{273}$ The role of planning and assessment in environmental law should at least remain stable, and there are many opportunities_ - particularly at state and local levels_-for greater use. $^{274}$

\section{Making Environmental Trading Systems Work}

A second recurring challenge of environmental law involves turning the theoretical appeal of environmental trading systems into practical results. In theory, the appeal of trading systems is elegantly simple: by allowing exchanges across large geographic areas and through time, trading systems should allow regulated actors to efficiently allocate the burdens of compliance while still attaining the desired environmental result. ${ }^{275}$ But that theory works best when relatively large actors trade fungible things, and in practice, such simplicity and fungibility

${ }^{272}$ See generally Wendy E. Wagner, The Triumph of Technology-Based Standards, 2000 U. ILL. L. REV. 83 (arguing that technology standards are an important hedge against information deficits); Karkkainen, supra note 261, at 907-08 (promoting adaptive management in contexts of uncertainty).

${ }^{273}$ See, e.g., Owen, supra note 263, at 282 n.93 (quoting EPA employees describing successful air quality planning processes).

${ }^{274}$ See MANDELKER, supra note 264, at $\$ 1: 7$ (noting that fifteen states have statutes like NEPA).

${ }^{275}$ E. Donald Elliott \& Gail Charnley, Toward Bigger Bubbles, F. APPLIED RES. \& PUB. POL'Y, 48 (1998); Robert Stavins, Market-Based Environmental Policies: What Can We Learn from U.S. Experience (and Related Research)?, in MOVING TO MARKETS, supra note 89, at 20. 
are rare. ${ }^{276}$ They are particularly rare for the kinds of impacts typically generated by

development. Development often involves large numbers of relatively small actors and actions, and for most of the impacts it generates_-filling wetlands, increasing water withdrawals, or generating air pollution, to provide just a few examples — context does matter. ${ }^{277}$ Consequently, each trade creates a risk that balance of benefits and burdens will somehow be skewed, with the imbalance operating to the detriment of environmental protection. ${ }^{278}$

Market designers can respond to those complications in several ways, but each traditional option is problematic. One option, which provides little assurance of environmental benefit, is to simply live with skewed outcomes. ${ }^{279}$ Alternatively, regulators can impose offset ratios, which will compensate for non-fungibility by imposing a sort of tax on transactions. ${ }^{280}$ Thus, for example, the developer who destroys one acre of wetlands might be required to construct four new acres. That approach may provide better environmental protection, but the tax undermines the economic appeal of the market. ${ }^{281}$ A third alternative is for regulators to review each trade, making sure it provides sufficient environmental value. That approach may ensure equivalence, but regulators will have much more work to do, and unpredictability and higher transaction costs may deter market participation. ${ }^{282}$ Incremental review also may squander the efficiency that might come from integrating individual trades into a broader plan. ${ }^{283}$ Regulators do use all of

${ }^{276}$ See Salzman \& Ruhl, supra note 89, at 622-30 (describing examples of non-fungibility).

${ }^{277}$ See id. at 342 (discussing the challenges of using trading systems to address habitat); Freyfogle, supra note 97, at 31-33 (describing the importance of context to water rights trading).

${ }^{278}$ See Tietenberg, supra note 89, at 87 (describing this risk).

${ }^{279}$ See Salzman \& Ruhl, supra note 89, at 612.

${ }^{280}$ See, e.g. 42 U.S.C. $\$ 7511 \mathrm{a}(\mathrm{e})(1)$ (2006) (establishing ratios for ozone emission offsets).

${ }^{281}$ See Stavins, supra note 275, at 26 (noting this disincentive).

${ }^{282} I d$. at 25 (" $[\mathrm{R}]$ equiring prior government approval of individual trades may increase uncertainty and transaction costs, thereby discouraging trading. ...”).

${ }^{283}$ See Jessica B. Wilkinson \& Robert Bendick, The Next Generation of Mitigation: Advancing Conservation through Landscape-Level Mitigation Planning, 40 ENVTL. L. REP. 10023, 10025 (2010); James H. Thorne et al., Evaluating Aggregate Terrestrial Impacts of Road Construction Projects for Advanced Regional Mitigation, 43 ENVTL. MGMT. 936, 937 (2009). 
these approaches, and many trading systems still do exist. ${ }^{284}$ But because of the resulting complications, some commentators question whether markets offer desirable options outside of a few exceptional circumstances. ${ }^{285}$

Advances in spatial analysis can support a promising alternative approach. Rather than relying on regulated entities to identify their preferred mitigation option, regulators can preapprove a set of mitigation options. Thus, for example, wetlands regulators can identify areas with high restoration potential, or where high-value wetlands are under threat, and can specify those areas as pre-approved mitigation zones. Developers then would receive expedited approval for trades involving mitigation in those areas. In theory, all participants benefit. Regulators and the public receive better assurance that individual trades will protect environmental values and will fit into a coherent larger plan, and developers avoid the uncertainty and delay associated with protracted review of each individual transaction.

This basic concept is not new, ${ }^{286}$ and it does not necessarily require spatial analysis, ${ }^{287}$ but in several ways, spatial analysis can make this alternative approach much more effective. Initially, spatial analysis can inform decisions about the scale and construction of the trading

\footnotetext{
${ }^{284}$ See generally Tietenberg, supra note 89, at 63-64 (describing many uses of environmental trading systems).

285 See Salzman \& Ruhl, supra note 99, at 342

${ }^{286}$ See, e.g., Buchsbaum, supra note 70, at 194-95 (describing habitat conservation planning under sections 9 and 10 of the ESA. HCPs often rely on directed trading); EMMONS \& OLIVIER RESOURCES, INC., LINO LAKES SPECIAL AREA MANAGEMENT PLAN 3-4 (2010), available at http://www.ricecreekwatershed.govoffice2.com/vertical/Sites/\%7BF68A5205-A996-4208-96B52C7263C03AA9\%7D/uploads/Lino_SAMP_Edited_Oct_10.pdf (describing several "Special Area Management Plans," which the Army Corps of Engineers sometimes uses to implement a similar regulatory approach); Julian Conrad Juergensmeyer et al., Transferable Development Rights and Alternatives after Suitum, 30 URB. LAW. 441, 433-54 (1998) (describing transferable development rights, which local governments use to direct development to growth areas and compensate landowners in areas where growth is to be limited); Royal C. Gardner, Banking on Entrepreneurs: Wetlands, Mitigation Banking, and Takings, 81 IowA L. REV. 527, 550-76 (1996); Gregory M. Parkhurst \& Jason F. Shogren, Incentive Mechanisms, in THE ENDANGERED SPECIES ACT AT THIRTY: RENEWING the CONSERVATION Promise 247, 249 (Dale D. Goble et al. eds., 2003) (describing habitat conservation banking)
} 
system. By using spatial models, analysts can approximately predict how much development is likely, where it will likely occur, and what kinds of impacts that development will likely create. ${ }^{288}$ That information in turn can help assess what sort of mitigation is needed, and also how much. ${ }^{289}$ Similarly, spatial models can predict how much economic value a trading program can generate, which in turn can help regulators set fee or offset schedules and determine how much mitigation work they will be able to do. ${ }^{290}$ All of this information can help regulators decide on the scale and mechanics of the trading program, as well as helping them determine whether a trading program will be viable at all.

Additionally, spatial analysis can help maximize the return on mitigation purchases. Analysts routinely use spatial

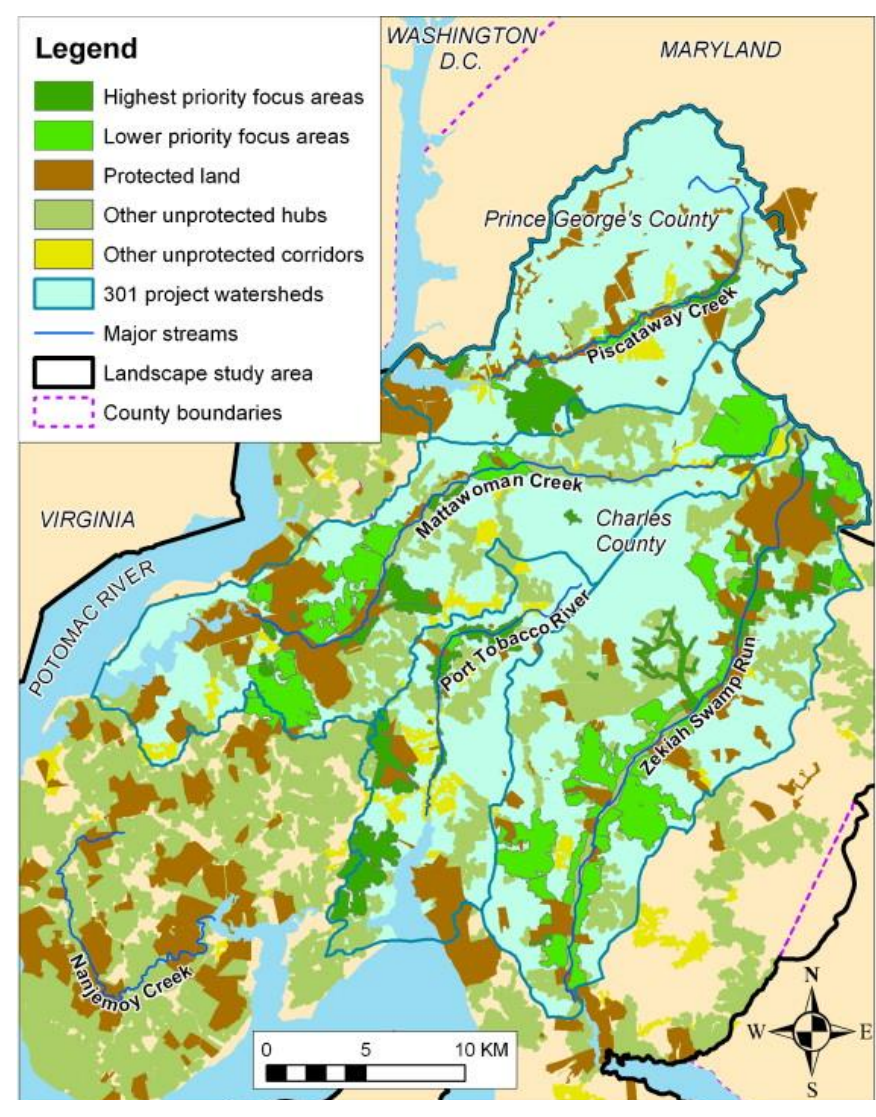

Figure 6: Targeted mitigation zones generated by combining multiple spatial databases. From Weber \& Allen, supra note 22, at 251. analysis to identify areas with multiple features desirable for some use, whether that use is a

${ }^{288}$ See, e.g. Thorne et al., supra note 283, at 939-40 (describing the use of a GIS for this initial step); Patrick D. Huber et al., Regional Advance Mitigation Planning: A Pilot Study Integrating Multi-Agency Mitigation Needs and Actions within a Comprehensive Ecological Framework, at https://rampcalifornia.water.ca.gov/documents/18/949688/Huber_etal_ICOET_final.pdf (describing a similar process).

289 See, e.g., Thorne et al., supra note 283, at 941-45 (summarizing regional mitigation needs).

${ }^{290} \mathrm{I}$ am currently a minor participant in an effort to use this approach to allow locally-led vernal pools regulation. See generally Community-Based Conservation: Maine Vernal Pools, at http://www.umaine.edu/vernalpools/ (last visited January 23, 2012) (describing the project, though focusing primarily on earlier phases). 
housing development or a conservation purchase, and that same approach can be adapted to target mitigation efforts. ${ }^{291}$ Regulators also can use development models to identify areas where, absent mitigation purchases, development would be likely to occur. ${ }^{292}$ That identification could reduce the "additionality" problems that result when public money is expended to protect resources not under any realistic threat. ${ }^{293}$ Spatial analysis also can link individual purchases into a coherent larger plan. By analyzing not just the individual value of each protection or restoration project, but also the potential interconnections between different mitigation areas, analysts can create synergy among separate transactions. ${ }^{294}$ Similarly, if a central goal of the trading scheme is to keep mitigation in relatively close geographic proximity to the impacted site, modelers can add a geographic-preference criterion to the site selection algorithm. ${ }^{295}$

All of these advances have value within a single-purpose trading system, where the goal is simply to protect wetlands, farmland, or habitat for one particular endangered species. But spatial modeling also raises the possibility of coordinating multiple trading systems. ${ }^{296}$ The core concept is similar: instead of selecting sites based on one environmental value, the model could select sites based on their value for multiple species, wetlands protection, water supply protection, and recreation. ${ }^{297}$ By prioritizing multiple targets, the program also could facilitate

${ }^{291}$ See supra notes 227-236 and accompanying text (discussing land use suitability analyses).

292 See, e.g., Theobald, supra note 217 (using biological and socio-economic data to identify ecologically valuable areas likely to be developed); Lohse et al., supra note 233, at 469 (describing the combined use of ecological, land use, and hedonic models to identify priority sites).

293 See Bruce A. McKenney \& Joseph M. Kiesecker, Policy Development for Biodiversity Offsets: A Review of Offset Frameworks, 45 ENVTL. MGMT. 165, 170-71 (2010) (identifying additionality as a key challenge).

294 See Thorne et al., supra note 283, at 937.

295 See Joseph M. Kiesecker et al., A Framework for Implementing Biodiversity Offsets: Selecting Sites and Determining Scale, 59 BIOSCIENCE 77, 80-81 (2009) (factoring geographic proximity into the site prioritization process).

296 See, e.g, Huber et al., supra note 288 (describing a multi-agency mitigation strategy); Weber \& Allen, supra note 22 (describing the use of multiple criteria).

${ }^{297}$ See, e.g., Weber \& Allen, supra note 22. 
an integrated response to mitigation requirements set by several different laws. ${ }^{298}$ Indeed, as integrated urban modeling becomes more and more advanced, it may become possible to integrate impacts on vehicle miles traveled, and therefore air quality protection and climate impacts, and perhaps also non-environmental values like infrastructure costs, into the trading exercise. ${ }^{299}$ The end result could be a trading system based on pre-approved receiving zones, all selected to maximize a broad set of environmental and non-environmental goals.

These kinds of integrative trading systems are still quite new, and schemes integrating a full suite of environmental goals do not yet exist. If and when they do, they will be highly imperfect systems, for they too will suffer from all the standard problems with any approach dependent upon quantitative environmental modeling. ${ }^{300}$ But the potential benefits are significant. Despite their flaws, trading systems already pervade environmental regulation, and improvements that ameliorate some of the externalities and inefficiencies of those existing systems therefore could have immense value, even if the reforms are only partial. These advances also could make trading feasible in many areas where it is not currently used. That also is a potentially significant gain. Often the practical alternative to the existence of a trading scheme is widespread tolerance of small environmental impacts, as regulators decline to impose prohibitory regulatory approaches they perceive as overly stringent. ${ }^{301}$ In these circumstances, the flexibility afforded by a trading program can provide a practicable way of securing some compensation for impacts that otherwise would go unregulated. ${ }^{302}$

${ }^{298}$ See, e.g., Huber et al., supra note 288.

${ }^{299}$ For a proposal for air quality trading using a spatially explicit model, see Jonathan Remy Nash \& Richard L. Revesz, Markets and Geography: Designing Marketable Permit Schemes to Control Local and Regional Pollutants, 28 ECOLOGY L.Q. 569 (2001).

${ }^{300}$ See supra notes 165-170 and accompanying text (discussing modeling's limits).

${ }^{301}$ See, e.g., Owen, supra note 6, at 192-94 (describing potential benefits of trading schemes for critical habitat protection).

302 See, e.g., id. at 193-94. 
These changes therefore should transform how environmental lawyers evaluate trading systems. Any time such systems are proposed, a key question is whether informational challenges will be manageable or, alternatively, will create a Hobson's choice between an efficient system that provides no environmental benefit and a protective system that is dysfunctionally cumbersome. In the future, answers to that question will often depend in part on the ability of spatial analysis to support the trading scheme. Where spatial tools allow better planning and oversight, environmental trading schemes should present viable options, even, sometimes, in circumstances where twenty years ago a trading scheme would have been infeasible or unwise.

\section{Who Regulates: Toward a More Functional Federalism}

Just as advances in spatial analysis will affect which environmental problems we attempt to address and how we address them, they also have implications for some of environmental law's traditional who questions: which entities, within or outside government, should address environmental problems, and how, if at all, should those entities coordinate their efforts? Those questions will likely emerge in a variety of contexts, but one in particular implicates foundational questions about our systems of environmental law. By facilitating increased understanding of environmental trends and improved communication about those trends, spatial analysis can help complex systems of overlapping federalism work.

For decades, environmental policymakers and scholars have been obsessed with federalism. The subject looms large in the Supreme Court's environmental jurisprudence, ${ }^{303}$

${ }^{303}$ See, e.g., Rapanos v. United States, 547 U.S. 715, 738 (2007) (rejecting a regulatory interpretation that would establish the U.S. Army Corps of Engineers as "a de facto regulator of immense stretches of intrastate land"); Solid Waste Agency of N. Cook Cnty. v. U.S. Army Corps of Eng'rs, 531 U.S. 159, 174 (2001) (rejecting a regulatory interpretation that "would result in a significant impingement of the States' traditional and primary power over land and water use"). 
pervades political rhetoric, ${ }^{304}$ and generates reams of academic articles. Somewhat overbroadly speaking, the debaters can be divided into two camps. On one side are the "dual federalists,",305 whose thinking is most clearly exemplified by several recent decisions of the Supreme Court. ${ }^{306}$ In their view, federalism functions best as a system of boundary rules protecting state and local governments from federal interference and insulating federal prerogatives from state and local intermeddling. ${ }^{307}$ Importantly for Greenacres, land use planning implicates a particularly important divide. The court has often asserted that even as the federal government takes the lead in environmental regulation, land use should remain "a quintessential state and local power."308 On the other side are the "interactive" or "dynamic" federalists. ${ }^{309}$ Like the dual federalists, they see value in a system with federal, state, and local authority. But they argue that jurisdictional overlap can promote collaboration and communication, leading to more effective use of the "laboratories of democracy" that federalism is supposed to promote. ${ }^{310}$

Many differences of opinion divide these camps, but one potentially important—albeit largely implicit and unexamined-divide involves assessments of the capacity for effective

${ }^{304}$ See Erin Ryan, Negotiating Federalism, 52 B.C. L. REV. 1, 1 (2011) (describing recent debates in which federalism assumed prominence).

305 This term comes from Robert A. Schapiro, From Dualist Federalism to Interactive Federalism, 56 EMORY L.J. 1, 4 (2006).

${ }^{306}$ See, e.g., Bond v. U.S., 131 S.Ct. 2355, 2364-65, _ U.S. _ (2011); Alden v. Maine, 527 U.S. 706, 714$15,748-52$ (1999).

${ }^{307}$ See Bond, 131 S.Ct. at 2364 ("The federal balance is, in part, an end in itself, to ensure that States function as political entities in their own right."); United States v. Morrison, 529 U.S. 598,599 (2000) ("The Constitution requires a distinction between what is truly national and what is truly local...."); Alden, 527 U.S. at 751 (rejecting authority that "would blur... the distinct responsibilities of the State and National Governments").

${ }^{308}$ Rapanos v. United States, 547 U.S. 715, 738 (2007); see Solid Waste Agency of N. Cook Cnty. v. U.S. Army Corps of Eng'rs, 531 U.S. 159, 174 (2001) (rejecting wetlands regulations partly because of impacts on state and local land use authority); Cal. Coastal Comm'n v. Granite Rock Co., 480 U.S. 572, 587 (1987) (emphasizing a distinction between land use planning and environmental protection).

${ }^{309}$ See, e.g, Hari Osofsky, Diagonal Federalism and Climate Change: Implications for the Obama Administration, 62 AlaBAmA L. REV. 237, 241-42 (2011); Heather K. Gerken, The Supreme Court 2009 Term, Foreword: Federalism all the Way Down, 124 HARV. L. REV. 4 (2009); Schapiro, supra note 305; Kirsten H. Engel, Harnessing the Benefits of Dynamic Federalism in Environmental Law, 56 EMORY L.J. 159 (2006). These and authors also use several other terms to describe variations on this general theory.

${ }^{310}$ Schapiro, supra note 305 , at 8-9. 
communication among different levels of government. If that capacity is limited, then a system of rigid spheres of authority may make sense. ${ }^{311}$ Different levels of government otherwise would stumble across each other's efforts, with that interference often culminating in federal displacement of state or local discretion, and the isolating boundaries envisioned by the dual federalists could be necessary to preserve meaningful state and local governance. ${ }^{312}$ Conversely, if the potential for effective intergovernmental dialogue is high, different levels of governments should be able to communicate their needs and priorities, isolate areas of disagreement, and find common ground, and lawmakers need not worry quite so much about allowing federal or state environmental programs to affect local land use decisions. ${ }^{313}$

In several ways, spatial analysis can help answer that question, ${ }^{314}$ and a particularly illustrative set of examples involves processes called "alternative futures modeling." 315 These process use spatial analysis to model future land use scenarios. ${ }^{316}$ Modelers can develop the scenarios in a variety of ways, including working with people in the affected area to define scenarios they think are plausible or desirable. ${ }^{317}$ The modelers then test the implications of those scenarios for a variety of potential outputs, including development patterns, water quality,

${ }^{311}$ Alternatively, consolidating authority within a single, unitary government might make sense, but that possibility is so politically unthinkable that I do not consider it here.

312 See generally Bond v. U.S., 131 S.Ct. 2355, 2364-65, _ U.S. _ (2011) (arguing that federalism protects liberty by protecting spheres of state and local primacy).

${ }^{313}$ To put the point slightly differently, if we are choosing between a federalism of voice and a federalism of exit, we need to know about the effectiveness of the means of communication. Compare Gerken, supra note 309 (promoting a federalism of voice) with Richard A. Epstein, Exit Rights under Federalism, 55 LAW \& CONTEMP. PROBS. 147, 147-49 (1992).

${ }^{314}$ Land use suitability analysis, which section III.B. describes at length, also has important implications for federalism, for it provides an effective mechanisms for communicating local, state, and federal regulatory constraints.

315 See, e.g., CARl Steinitz ET AL., Alternative Future fOr Changing LANDSCAPES: THE UPPER SAN PEDRO RIVER BASIN IN ARIZONA AND SONORA (2003); Tony Prato et al., Evaluating alternative economic growth rates and land use policies for Flathead County, Montana, 83 LANDSCAPE AND URBAN PLANNING 327 (2007); Baker et al., supra note 182. For warnings about limitations of alternative futures analysis, see Pontius, Jr. \& Neeti, supra note 211 , at 39.

316 See Pontius, Jr. \& Neeti, supra note 211, at 39.

317 See, e.g., Baker et al., supra note 182, at 315 ("The future landscapes are designed with stakeholder input to illustrate major strategic choices."). 
biodiversity, and, potentially, economic impacts like costs to state and local government and private property values. ${ }^{318}$ Based on the initial results, they also can develop new scenarios or work backward from desired future outcomes to recommended present policy approaches. ${ }^{319}$ The end result is generally a series of detailed maps that depict plausible alternative futures for the modeled area, as well as charts and graphs explaining differences between the alternatives. ${ }^{320}$

In several ways, these processes can facilitate the kind of interjurisdictional coordination upon which dynamic federalism theories implicitly rely. Initially, they allow evaluation of the combined implications of a variety of current trends and policies. ${ }^{321}$ That review may reveal future conflicts or opportunities that might never have become apparent through individual planby-plan or project-by-project studies. ${ }^{322}$ Futures modeling also allows participants to understand the potential implications of - and perhaps, to reconsider - their prior assumptions. By visually depicting tradeoffs between competing goals, modeling creates an opportunity to consider whether rigid adherence to their prior preferences will produce a landscape participants want to live in. ${ }^{323}$ For similar reasons, the process of developing a model and a set of maps provides an opportunity to move discussions out of the realm of ideological abstraction. ${ }^{324}$ Scenario maps grab attention and convey information in a language readily understood by many people, making

${ }^{318}$ See, e.g., Baker et al., supra note 182, at 316 (evaluating implications for water availability, riparian habitats, and terrestrial wildlife); Chakroborty, supra note 175, at 396-97 (describing a scenario-modeling exercise for Maryland).

319 See Baker et al., supra note 182, at 315 ("As stakeholders see results for the initial set of alternative futures, it may lead to new ideas or compromise positions that warrant design of additional features or analysis of additional endpoints.").

${ }^{320}$ See, e.g., U.S. Envt'1 Prot. Agency, Willamette Basin Alternative Futures Analysis: Environmental Assessment Approach that Facilitates Consensus Building, at http://www.epa.gov/wed/pages/projects/alternativefutures/ninepager.pdf.

${ }^{321}$ See, e.g., Baker et al., supra note 182, at 319 (describing a scenario that "provided a unique opportunity to examine [the] joint implications" of a variety of land use plans).

${ }^{322}$ See, e.g., id. (describing surprising results).

${ }^{323}$ See, e.g., Schmitt Olabisi et al., supra note 184, at 2693-94 (discussing an exercise that confronted participants with unexpected implications of a commitment to local energy production).

${ }^{324}$ See Hulse et al., supra note 173, at 339 (explaining how mapping exercises can facilitate constructive dialogue). 
a possible future seem much more real. ${ }^{325}$
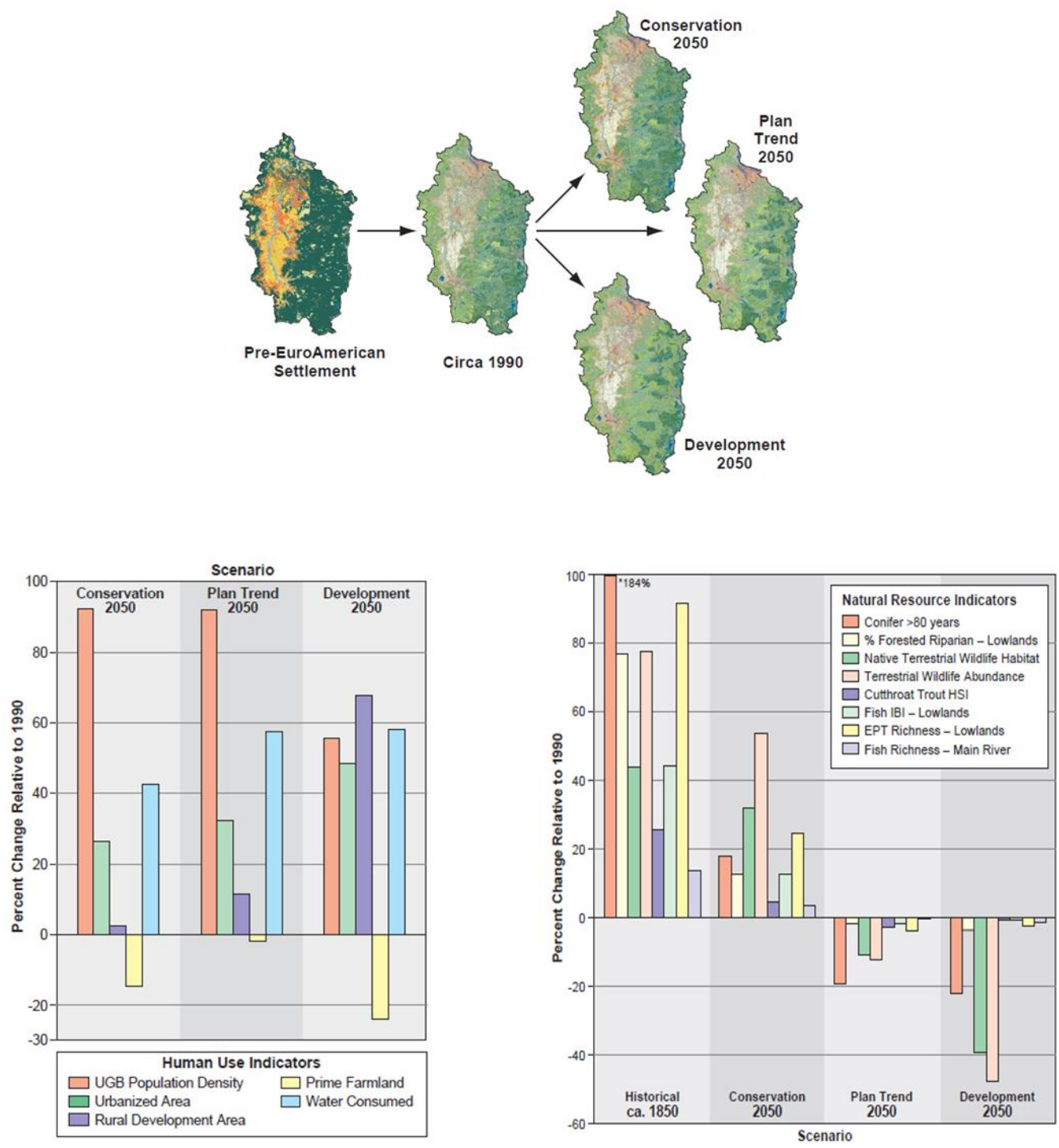

Figures 7, 8, and 9: Maps and charts from the Willamette Basin Alternative Futures Modeling Project. From U.S. Envtl. Prot. Agency, supra note 320. In actual public meetings, these maps would be poster-sized or larger, with much higher resolution, and details and contrasts would be easier to see.

${ }^{325}$ Yaakov Garb et al., Scenarios in society, society in scenarios: toward a social scientific analysis of storyline-driven environmental modeling, 3 ENVTL. RESEARCH LETTERS _, 3 (2008) (emphasizing the importance of dialogue about models and maps). Of course, participants may also discount scenarios that do not conform to their prior beliefs. See Lorenzoni \& Hulme, supra note 29, at 393-94. 
Facilitating a more inclusive and constructive discussion may be valuable, but if that discussion only reveals intractable conflict, the exercise ultimately will have only modest value. Often, however, modeling does reveal options that can ameliorate interjurisdictional tensions. ${ }^{326}$ Even environmentally sensitive regions often have many areas where development can occur while causing relatively modest environmental impacts. ${ }^{327}$ Similarly, if policymakers act proactively, many mechanisms, including protecting habitat corridors, promoting cluster development and other compact patterns of growth, and preserving riparian buffers, can help integrate development into a landscape while retaining important ecological functions. ${ }^{328}$ Prioritizing development in some areas and limiting it in others obviously has potential implications for property values, but advance planning allows communities the ability to set up financial mechanisms, like environmental trading systems or transferable development rights, to ameliorate those impacts. ${ }^{329}$ Alternatively, confronting the future implications of unrestrained development may lead people to conclude that some uncompensated limitation on property use is an appropriate contribution toward maintaining a community's identity and quality of life. ${ }^{330}$ In short, in a variety of ways, modeling alternative futures can help people achieve the goals of environmental law while still preserving ample local discretion and community autonomy.

${ }^{326}$ See, e.g., Prato et al., supra note 315, at 336 (concluding that a "moderately restrictive" land use policy could accommodate future growth).

327 See, e.g., McCloskey et al., supra note 177, at 198 (finding abundant opportunities for conflict-free development); John Van Sickle et al., Projecting the Biological Condition of Streams under Alternative Scenarios of Human Land Use, 14 ECOLOGICAL APPLICATIONS 368, 378 (2004) (concluding that a "conservation scenario" would allow environmental improvements even as the Willamette Valley's population doubles).

${ }^{328}$ See U.S. ENVTL. PROT. AGENCY, supra note 39, at 35-79 (describing smart growth mechanisms).

${ }^{329}$ See supra notes 275-302 and accompanying text (discussing trading systems); supra note Error! B ookmark not defined. and accompanying text (discussing transferable development rights).

${ }^{330}$ See generally ERIC FReYfogle, On PRIVATE PROPERTY: Finding COMMON GROUND ON THE OWNERSHIP OF LAND (2007) (arguing that because property derives its value from human communities, those communities should be able to use democratic processes to adjust property rights). 
To be clear, my claim is not that the emergence of spatial analysis will generate universal acceptance of dynamic federalism. There are many other reasons, including a generalized hostility to regulatory governance and ideological opposition to federal authority, supporting continued interest in federalism's more boundary-based forms, and the prospect of effective intergovernmental collaboration will not make that interest disappear. ${ }^{331}$ Similarly, spatial analysis will not always reveal options that meet everyone's needs. Some conflicts are intractable. ${ }^{332}$ But spatial analysis can communicate federal, state, and local goals, explore compatibilities between those goals, and cabin conflict to more manageable and discrete zones. That capacity should give at least a moment's pause to lawmakers and judges who assume that rigid limits on federal or state environmental regulation are necessary to protect spheres of state or local autonomy.

\section{Spatial ANALysis AND ENVIRONMENTAL LAW RESEARCH METHODOLOGIES}

So far, this Article has focused upon implications of spatial analysis for our understanding of environmental problems and for the design and implementation of legal solutions. Obviously that discussion should inform environmental law research, for the structure and application of environmental law are central research subjects for many, if not most, academic inquiries. But the implications of spatial analysis extend beyond the subjects of environmental law research and also implicate the methodologies. This section explores how. Again, the discussion here is illustrative and brief, but even a few examples should demonstrate

\footnotetext{
${ }^{331}$ It is very difficult to imagine, for example, that the venom currently directed at federal greenhouse gas regulation would disappear if those controls derived from the states.

${ }^{332}$ See, e.g., Albert, supra note 180, at 36-39, 41-42 (describing the minimal influence of one alternative futures modeling project).
} 
that quantitative spatial analysis can change how legal research is done. In turn, those research advances could facilitate improvements in the structure and application of environmental law.

For decades, assessing how environmental law changes real-world outcomes has often been difficult. Many environmental laws generate only partial implementation, and determining the extent of the gaps between the law on the books and the law in practice is not always easy. ${ }^{333}$ Even if something approaching full compliance exists, the consequences of that compliance can be difficult to assess. Determining the environmental benefits of NEPA, for example, is complicated by the attenuated causal chain between required actions and actual environmental outcomes. ${ }^{334}$ Environmental laws also often generate unintended consequences, and the nature and extent of those consequences is similarly difficult to predict. ${ }^{335}$ For all of these reasons, debate is still robust about whether and how some of our most familiar environmental laws provide environmental protection. ${ }^{336}$

Spatial analysis gives environmental law researchers new tools to address these questions. By comparing development patterns in areas subject to a particular law from development patterns in exempted areas, for example, researchers can assess how that law actually affects outcomes. ${ }^{337}$ Similarly, longitudinal studies, which examine development patterns before and after the imposition of some environmental constraint, could help assess what on-the-ground impact laws actually have. Each type of study involves complications; most

${ }^{333}$ See Farber, supra note 6, at 298-99 (describing the pervasiveness of such "slippage")

${ }^{334}$ See Robertson v. Methow Valley Citizens Council, 490 U.S. 332, 350-51 (1989) (holding that NEPA establishes no substantive constraint). The lack of substantive standards complicates efforts to identify actions taken because of NEPA.

${ }^{335}$ See, e.g., Lueck \& Michaels, supra note 28 (concluding that ESA section 9 has generated counterproductive incentives).

${ }^{336}$ See, e.g. Karkkainen, supra note 266, at 338 ("Observers hold divergent views on NEPA's effectiveness and its value as an environmental policy tool."); Owen, supra note 6, at 145-46 (summarizing debates about what one key ESA provision actually accomplishes).

${ }^{337}$ See, e.g., Irwin et al., supra note 26 (evaluating regulatory controls in the Chesapeake Bay watershed). 
importantly, the complexity of human and environmental systems assures a potential

overabundance of confounding variables. But with the increased availability of spatial data sets and with the possibility of using linear regressions to address complicated systems, the possibility of new insight exists.

This sort of research is not exactly new. For decades, economists have been using both theoretical models and actual datasets to test the implications of environmental laws. ${ }^{338}$ But such work rarely appears in legal journals, and even when it does, the authors usually are not lawyers. ${ }^{339}$ That is a significant absence. While an economist's perspective has obvious value, there are ways in which lawyers could contribute to this sort of work. Environmental lawyers may not be trained in quantitative analysis or GIS, but they are taught to understand, at least at a qualitative level, how particular regulatory provisions fit within broader environmental law systems, how environmental law evolves and changes, what roles environmental law assigns to different actors, and how different institutions tend to respond to their roles. That legal perspective could help interdisciplinary research teams identify important research questions, develop hypotheses, flag potentially confounding variables, and interpret results.

The rise of environmental modeling creates similar opportunities for engagement. One primary goal of many environmental modelers is to understand and simulate the feedback loops between human and natural systems. ${ }^{340}$ Those feedback loops are partly mediated by economics, for economic incentives play a significant role in determining human actions. Consequently, and not surprisingly, economists have engaged the process of modeling land use change. ${ }^{341}$ But the relationships between human and environmental systems are also heavily mediated by law.

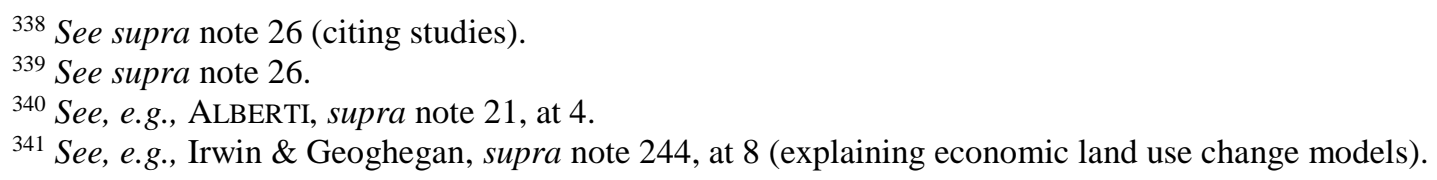


Though they have rarely played this role, lawyers could offer important insights about how legal rules and norms might generate environmental consequences, and about how environmental change generates legal responses. ${ }^{342}$ In some circumstances, that legal perspective should help modelers build better and more useful models. In others, environmental lawyers' insight may be that the dynamics are too complicated and unpredictable to model. But that also can be an important contribution, for it can send the modelers on to more useful endeavors.

\section{CONCLUSION}

In the 1960s, ecology emerged as a scientific discipline, and law has never been the same. ${ }^{343}$ The core concepts of ecology - its focus on interconnectedness, interdependence, and environmental fragility - energized an environmental movement and led to a generation of environmental laws. ${ }^{344}$ Similarly, the emergence of law and economics, quantitative risk analysis, and complexity theory all have had profound implications for the practice and theory of environmental law. ${ }^{345}$ Environmental law is inextricably, if sometimes uncomfortably, intertwined with environmental science, and when environmental science evolves, legal thinkers usually ask whether law should evolve too. ${ }^{346}$

${ }^{342}$ See generally LAZARUS, supra note 7 (exploring the dynamics that spurred the creation of American environmental law).

343 See Angelo, supra note 191, at 1527 ("Environmental law was born out of the new scientific understandings of ecology in the mid-twentieth century.").

${ }^{344}$ See Tarlock, supra note 191, at 1121-22, 1125-28 (describing ecology's role in environmental law's formation).

345 See Hornstein, supra note 191, at 565-69 (describing the rise of risk analysis); Lynne E. Blais, Beyond Cost/Benefit: The Maturation of Economic Analysis of the Law and its Consequences for Environmental Policy, 2000 U. ILL. L. REV. 237, 241-42; J.B. Ruhl, Complexity Theory as a Paradigm for the Dynamical Law-and-Society System: Wake-Up Call for Legal Reductionism and the Modern Administrative State, 45 DUKE L.J. 849 (1996).

346 See, e.g., Tarlock, supra note 191, at 1134-44 (considering potential reactions to the decline of ecology's equilibrium paradigm); Ruhl, supra note 345. 
The emergence of quantitative spatial analysis has just begun to spur a similar reaction. ${ }^{347}$ The products of spatial analysis often form the evidentiary basis for decisions required by environmental laws, and spatial analysts often work to fulfill environmental law's informational demands. But while environmental law has influenced spatial analysis, the feedback loop has not closed. Advances in spatial analysis have not led to any significant revisions to the structure, practice, or theory of environmental law. The time for greater engagement has come. Spatial analysis still is a relatively new field, and the technologies and theories it has spawned are by no means fully mature. In some ways, those technologies will always remain limited. But by helping environmental researchers and managers think across media-specific boundaries and spatial and temporal scales, and by facilitating communication and collaboration across jurisdictional boundaries, spatial analysis can help environmental law gain traction on some of its greatest challenges.

${ }^{347}$ See, e.g. Boyd, supra note 26 (considering the implications of spatial data for global climate change policy and forest management). 